Gerión. Revista de Historia Antigua

ISSN: 0213-0181

https://dx.doi.org/10.5209/geri.74784

\title{
Un enclave fronterizo entre las provincias hispanas: la difícil definición de la Bastetania y la identidad étnica bastetana en el s. II a.C. ${ }^{1}$
}

\author{
Jorge García Cardiel ${ }^{2}$
}

Recibido: 6 de marzo de 2020 / Aceptado: 19 de enero de 2021

Resumen. En el presente artículo hemos tratado de profundizar en las estructuras políticas, sociales, económicas y culturales que caracterizaron el devenir de las comunidades locales de la Bastetania durante la época posterior a la conquista romana. Las sierras y hoyas bastetanas constituyeron un escenario de retaguardia durante la Segunda Guerra Púnica y quedaron a caballo entre las dos provincias hispanas, lo que, unido a la dificultad de sus comunicaciones y a lo agreste de sus paisajes, dio pie a que durante el siglo II a.C. la zona se convirtiera en un auténtico enclave de frontera con una fuerte personalidad propia, sustancialmente distinta de las estructuras (más acusadamente) híbridas que habían comenzado a fraguar desde mucho antes en las regiones circundantes.

Palabras clave: iberos; conquista romana; romanización; provincialización; frontera.

\section{[en] A Frontier Enclave between the Hispanic Provinces: The Elusive Definition of Bastetania and the Bastetani Ethnic Identity in the Second Century BC}

Abstract. The present study deals with the political, social, economic and cultural dimensions of the local communities of Iberian Bastetania in the immediate aftermath of the Roman conquest. Bastetanian valleys and basins were a rearguard zone during the Second Punic War, and since then they were a peripheral region, halfway between the two Hispanic provinces. That, combined with the difficulties in communications and the complex orography, made this zone a frontier enclave with strong personality. Hence the substantial differences between Bastetanian structures and the (even more) hybrid structures that had begun to emerge in the surrounding regions a lot earlier.

Keywords: Iberians; Roman Conquest; Romanization; Provincialisation; Boundary.

Sumario: 1. Introducción: la difícil caracterización de la Bastetania. 2. La anexión romana de la Bastetania según las crónicas de guerra. 3. La transformación del territorio bastetano. 4. Los discursos ideológicos. 5. Conclusiones. 6. Referencias bibliográficas.

Cómo citar: García Cardiel, J. (2021): Un enclave fronterizo entre las provincias hispanas: la difícil definición de la Bastetania y la identidad étnica bastetana en el s. II a.C., en Gerión 39/1, 95-124.

\footnotetext{
1 Trabajo realizado en el marco del Proyecto I+D "Ciudades y complejos aristocráticos ibéricos en la conquista romana de la Alta Andalucía” (HAR 2017-82806-P). Quisiera expresar mi agradecimiento a su IP, F. Quesada, por su amabilidad a la hora de leer y comentar el borrador del presente texto.

2 Universidad Autónoma de Madrid - Grupo Occidens.

E-mail: jorge.garciac@uam.es

ORCID: 0000-0002-1093-8129
} 


\section{Introducción: la difícil caracterización de la Bastetania}

La caracterización de lo que los autores clásicos denominaron Bastetania constituye uno de esos problemas historiográficos irresolutos que periódicamente hacen correr ríos de tinta. ${ }^{3}$ Ello se debe tanto al carácter fragmentario, tardío y aparentemente paradójico de nuestras fuentes como a nuestras propias dificultades a la hora de dar con la metodología adecuada desde la que interpretar los datos disponibles. A resultas de ello, todavía en la actualidad los distintos autores otorgan al término "Bastetania" connotaciones políticas, territoriales y cronológicas muy distintas, sin que por el momento se haya conseguido alcanzar una solución de compromiso.

El problema parte de la propia evanescencia del corónimo. A priori, podríamos pensar que nos encontramos ante una de esas entidades estatales o protoestatales que surgieron al socaire de la Segunda Guerra Púnica en torno a una capital y un caudillo militar, tales como la Edetania o la Oretania. ${ }^{4}$ Para el caso de la Bastetania, sin embargo, la situación no está tan clara, pues las fuentes no aluden a ningún dirigente epónimo, y la ciudad de Basti (en el caso de que pudiera identificarse, como parece, con Cerro Cepero, Baza, Granada $)^{5}$ no tendría seguramente la entidad suficiente como para haber logrado imponer su capitalidad sobre el resto de los núcleos de la región. Es más, su nombre no aparece mencionado hasta época tardía en el Itinerario de Antonino, ${ }^{6}$ silencio este que consideramos sumamente significativo. Para solventar el problema, en alguna ocasión se ha propuesto que los autores clásicos habrían construido el corónimo haciéndolo derivar erróneamente de la que en realidad no era sino una más de las ciudades bastetanas, bien por su ubicación central en la región y su papel redistribuidor de las mercancías llegadas desde la costa, ${ }^{7}$ o bien, según proponen E. Ferrer y F. Prados, a partir de una falsa etimología que habría ligado Basti con un antiguo etnónimo transmitido por las fuentes feniciopúnicas, "mastienos", alusivo a la ciudad de Mastia, localizable en el entorno del Estrecho de Gibraltar. ${ }^{8}$

En todo caso, estas consideraciones irresolutas sobre el posible carácter etic del corónimo "Bastetania" nos conducen a su vez a dos nuevos interrogantes: ¿a qué aludía en realidad dicho término? ¿Y hasta qué punto esa realidad sería preexistente a la aparición del mismo en las fuentes grecorromanas? Aunque con matices, la mayor parte de la historiografía coincide en que la Bastetania sería una región poblada por toda una serie de comunidades culturalmente afines entre sí y estrechamente conectadas en lo económico, pero políticamente independientes. Algunos autores han tratado de llevar la interpretación un paso más allá, defendido por ejemplo que las comunidades bastetanas convergieron políticamente para enfrentarse a los ejércitos cartagineses y romanos, ${ }^{9}$ pero las crónicas que nos hablan de dichas guerras,

\footnotetext{
García Moreno 1990; Pastor Muñoz 1993; Marín Díaz - Pérez Cruz 1996; Pérez Cruz 1997; González Román - Adroher Auroux 1999; Ferrer Albelda - Prados Pérez 2001-2002; Lorrio Alvarado 2007; Adroher Auroux 2008, 212-214; Garcés Estallo 2008; Gozalbes Cravioto 2008; López Castro - Adroher Auroux 2008; López Mondéjar 2008; Quesada Sanz 2008; Salvador Oyonate 2011; 2015; López Mondéjar 2018.

Vid., por ejemplo, González Román 1992, 157.

Pastor Muñoz 1993, 215; Caballero Cobos 2008, 299-300.

It. Ant. 401.5; 402.5 .

Adroher Auroux 2008, 212.

Ferrer Albelda - Prados Pérez 2001-2002. Contra, cf. Salvador Oyonate 2015; López Mondéjar 2018, 48-49.

Blech 2008, 98.
} 
como veremos más adelante, parecen apuntar en sentido opuesto. Otros, en cambio, han propuesto que Roma pergeñaría este concepto para referirse a unos territorios conquistados de límites imprecisos situados entre las regiones más homogéneas polarizadas en torno a Carthago Nova y al Alto Guadalquivir; ${ }^{10}$ o bien que el Estado romano crearía la regio Bastetana como una unidad de recaudación fiscal, en el marco de unos primeros años de expansión imperial por el Mediterráneo que entrañaron no pocas dosis de experimentación administrativa; ${ }^{11}$ hipótesis esta última muy sugerente, pero que ni prueba ni refuta la posible existencia de una identidad bastetana previa al contacto con Roma.

Tampoco tenemos claras cuáles fueron las fronteras de la Bastetania, pues las informaciones que nos transmiten al respecto las fuentes clásicas son, al menos en algunos puntos, contradictorias. ${ }^{12}$ Ante tales desajustes, algunos autores han apostado por diferenciar entre una "Bastetania" prerromana y una "Bastitania" creada por Roma por motivos fiscales, ${ }^{13}$ en tanto que otros prefieren pensar en una región étnica sin límites definidos, habida cuenta de la movilidad y de los continuos procesos de redefinición identitaria de las comunidades locales durante un período convulso, y de la heterogeneidad de las fuentes consultadas por los autores clásicos. ${ }^{14}$

No mucha más fortuna han tenido los arqueólogos que se han afanado en caracterizar la Bastetania desde el punto de vista de su registro material. Un trabajo seminal en este sentido fue el de M. Almagro, ${ }^{15}$ quien señaló las tumbas de cámara y las cajas cinerarias de piedra como marcadores arqueológicos de la etnia bastetana, restringiendo esta, por consiguiente, a los altiplanos y las hoyas de la Alta Andalucía. En la década siguiente, nuevos trabajos aportaron al análisis un mayor refinamiento metodológico y nuevos indicadores materiales. T. Chapa y J. Pereira ${ }^{16}$ caracterizaron la Bastetania como un espacio de negociación cultural entre lo ibero y los influjos púnicos de la costa almeriense, negociación que se plasmó, además de en las citadas cajas de piedra y las tumbas de cámara, en el recurso generalizado a las cráteras áticas como urnas cinerarias, en el empleo de cerámica ibérica pintada y en la recurrencia de la iconografía del ciervo, elemento este último que extendió el territorio pretendidamente bastetano por el sur albaceteño, de acuerdo con Ptolomeo. De ámbito más local fueron los estudios de A. Ruiz, C. Rísquez y F. Hornos ${ }^{17}$ y de F. Quesada, ${ }^{18}$ quienes trataron de deducir la frontera étnica entre los bastetanos y los turdetanos a partir de las diferencias en los patrones de poblamiento y el armamento, respectivamente; o el de L. López Mondéjar, ${ }^{19}$ quien recientemente hizo lo propio en los altiplanos murcianos para concretar el límite entre bastetanos y contestanos. Las escasas excavaciones en extensión desarrolladas en el corazón de la región, finalmente, han permitido proponer una facies cerámica paradigmática,

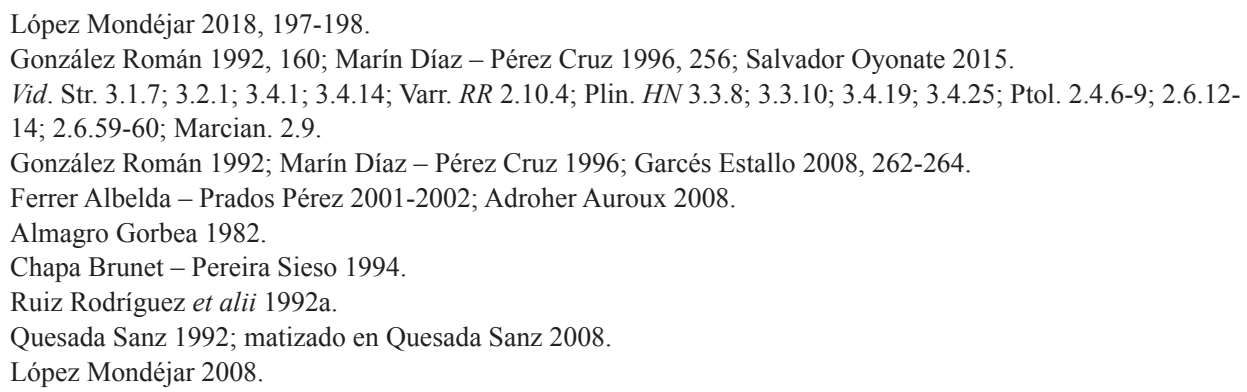


característicamente "bastetana" según sus postulantes. ${ }^{20}$ Ahora bien, todos estos trabajos adolecen, como muchos de sus autores asumen con prudencia, de dos graves problemáticas: la dificultad epistemológica de discriminar vestigios materiales como supuestos indicadores de afinidades de tipo étnico ${ }^{21} \mathrm{y}$, sobre todo, la circunstancia de que la mayoría de ellos estudiaron la distribución de restos arqueológicos propios de los siglos V y IV a.C. para delimitar una región étnica de la que solo tenemos constancia documental a partir de finales del siglo III a.C., y aún entonces a través del filtro de autores grecorromanos de época altoimperial. Es más, la distribución de los indicadores arqueológicos aludidos (y de alguno más postulado en trabajos más recientes, como los llamados "santuarios bastetanos", de los que más tarde hablaremos) no concuerda entre sí. En conjunto, pues, estos trabajos hablan de una cierta afinidad cultural entre las comunidades de los altiplanos y hoyas del sureste peninsular, pero difícilmente servirán para establecer fronteras definidas entre estas comunidades y sus vecinas, y mucho menos nos ayudarán a poner algo de orden entre los recuentos etnogeográficos de los autores clásicos. ${ }^{22}$

Ante tantas dificultades para caracterizar eso que las fuentes clásicas denominaron "Bastetania", en las presentes páginas nos proponemos abordar el asunto desde una perspectiva ligeramente diferente. Para empezar, permítasenos señalar que, para evitar continuos circunloquios y con una finalidad meramente práctica, en las páginas subsiguientes utilizaremos el corónimo "Bastetania" y sus derivados con un sentido geográfico, referido básicamente a las depresiones cordobesas, el medio y alto Genil, los altiplanos y hoyas granadinas y el campo de Bugéjar, es decir, la zona nuclear de la realidad territorial a la que la práctica totalidad de los autores, antiguos y modernos, se vienen refiriendo cuando hablan de la Bastetania. No pretendemos, pues, determinar con precisión cuáles fueron sus fronteras, explorar las realidades identitarias locales que pudieran esconderse tras el corónimo empleado por las fuentes grecorromanas, ni analizar el significado que estos últimos autores daban al concepto. En cambio, a lo largo de las siguientes páginas nos preguntaremos, para empezar, a qué se debe la escasez y el carácter tardío y a menudo contradictorio de nuestras fuentes. Algunos autores han achacado el desconocimiento relativo de los autores clásicos a la pertinaz resistencia de los bastetanos ante la dominación romana, ${ }^{23}$ en tanto que otros investigadores lo vinculan a una relativa falta de conflictividad de las poblaciones locales. ${ }^{24} \mathrm{La}$ continuidad de buena parte del repertorio cerámico ibérico hasta momentos llamativamente tardíos de la época imperial es recalcada por los primeros como argumento, en tanto que la llegada de importaciones itálicas desde comienzos del siglo II a.C. (palmaria en ciertas zonas de la Bastetania, pero no en otras, como matizaremos más adelante) es subrayada por los segundos como evidencia de la presencia de gentes itálicas conviviendo pacíficamente (al menos en términos generales, habida cuenta de lo cambiante y convulso del período) con las comunidades locales. ${ }^{25}$

$\mathrm{Y}$ es que los procesos históricos suelen ser demasiado complejos como para abarcarlos mediante dicotomías sencillas como "resistencia-pacificación". Un

\footnotetext{
Vaquerizo Gil et alii 2001, 235-236.

Fernández Götz 2009.

López Mondéjar 2018.

Vid., en último lugar, Garcés Estallo 2008.

Gozalbes Cravioto 2000; Bravo Carrasco et alii 2004.

Adroher Auroux et alii 2002, 106-107; Román Punzón 2009, 236.
} 
reciente trabajo sobre la zona noreste de la Hispania Citerior, por ejemplo, pone de manifiesto que el alejamiento de los principales frentes bélicos y el consiguiente silencio de los autores grecorromanos no entrañan necesariamente la "pacificación" absoluta de una región, que por el contrario puede estar viéndose sometida a fuertes tensiones propias de los escenarios de retaguardia. ${ }^{26}$

Para intentar comprender mejor todos estos procesos, proponemos abordar la cuestión desde una triple perspectiva, que será la que estructurará las siguientes páginas: los episodios de conflictividad militar que nos transmiten las fuentes, las transformaciones en la estructura del poblamiento y las pautas de explotación de los recursos, y la singularidad y perdurabilidad de los discursos ideológicos locales. No es este un planteamiento original, desde luego, pero el esfuerzo de síntesis que entraña acaso sí que lo sea. Solo así profundizaremos en las estructuras de un mundo multipolar como el de la Hispania del siglo II a.C., en el que las diversas comunidades y los distintos agentes sociales reaccionaron de una manera diversa ante el proceso imperialista romano según sus respectivas agendas, y en el que tanto dicho proceso imperialista como dichas agendas fueron evolucionando con el tiempo. Un mundo en el que, como parece que sucedió en la Bastetania, se podían concitar el desinterés de los autores grecorromanos (¿y acaso también de la administración romana?) y la llegada de productos fabricados en Italia; la preservación de las formas de vida tradicionales y la actuación de ciertos agentes mediterráneos deseosos de prosperar gracias a las oportunidades que un territorio periférico provincial les deparaba.

\section{La anexión romana de la Bastetania según las crónicas de guerra}

Las referencias a la Bastetania en el contexto de la Segunda Guerra Púnica escasean. La primera de ellas, no obstante, podría ser anterior a lo que la historiografía viene dando por sentado. Aunque Polibio nunca empleó el etnónimo "bastetanos", si aceptáramos la ya mencionada hipótesis acerca de la identificación entre los "bastetanos" de los autores grecorromanos y los "mastienos" de las fuentes púnicas, ${ }^{27}$ tendríamos que reparar en que, entre los preparativos bélicos que Aníbal hizo consignar en el cabo Lacinio, figuraba el envío a África de un amplio contingente

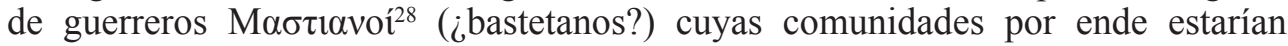
cooperando (voluntaria o forzosamente) con la causa cartaginesa.

Una vez comenzado el conflicto, no obstante, las armas romanas no irrumpirían en la Bastetania hasta 214 a.C. ${ }^{29}$ cuando, tras romper el asedio de Iliturgi, Cneo Cornelio Escipión espoleó a sus legiones hacia Bigerra, que al igual que Iliturgi estaba siendo sitiada por los cartagineses por haberse declarado partidaria de la causa

\footnotetext{
Naco del Hoyo 2017.

Ferrer Albelda - Prados Pérez 2001-2002.

Plb. 3.33.9.

9 Aunque Pastor Muñoz 1993, 223-224, defiende que la primera ciudad bastetana en tomar parte en el conflicto fue Turbula (Ptol. 2.6.60), pues sus habitantes solicitaron amparo a Aníbal frente a Sagunto, la cuestión no está

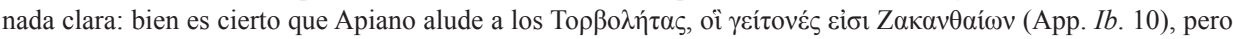
Livio, más próximo en el tiempo a los hechos, los llama “turdetanos” (Turdetanis: Liv. 21.6.1).
} 


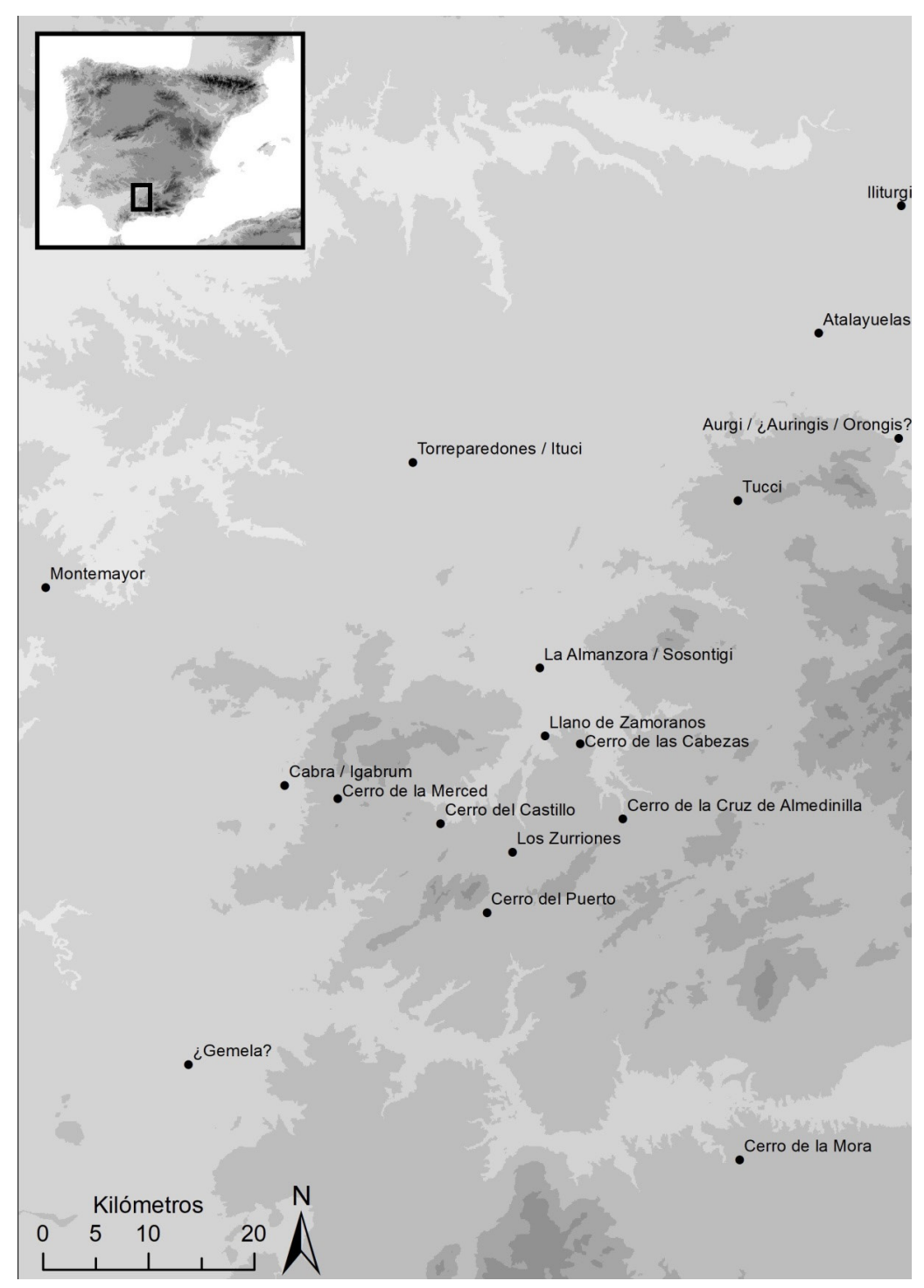

Fig. 1. Topónimos mencionados en el texto: Bastetania occidental (elaboración propia)

romana. ${ }^{30}$ Roto también este asedio, los romanos continuaron camino hacia Munda, donde batieron a sus enemigos, y de ahí a Auringis, donde volvieron a hacer lo propio, poco antes de la inminente debacle de las armas romanas. Ahora bien, la identificación de todos estos topónimos es problemática. Sabemos que Iliturgi corresponde con Cerro Máquiz (Mengíbar, Jaén), ${ }^{31}$ pero más compleja es la identificación de Bigerra, que Ptolomeo caracteriza de " $\beta \alpha \sigma \tau \imath \tau v v o l ": 32$ la narración 
liviana de la campaña hace pensar en una localización granadina, que una parte de la historiografía ha puesto en relación con el Cortijo de Becerra (Granada), ${ }_{3}^{33}$ Bogarre (Píñar, Granada), ${ }^{34}$ o Los Allozos (Montejícar, Granada). ${ }^{35}$ En cambio, la línea interpretativa que opta por situar este topónimo en Bogarra (Albacete) ${ }^{36}$ no concuerda con la circunstancia de que, desde Bigerra, las legiones romanas persiguieron a los cartagineses "a toda prisa" hasta Munda (de localización asimismo incierta, aunque se suele suponer en el Bajo Genil) ${ }^{37}$ y Auringis (asimilable a Aurgi, bajo la actual ciudad de Jaén). ${ }^{38}$

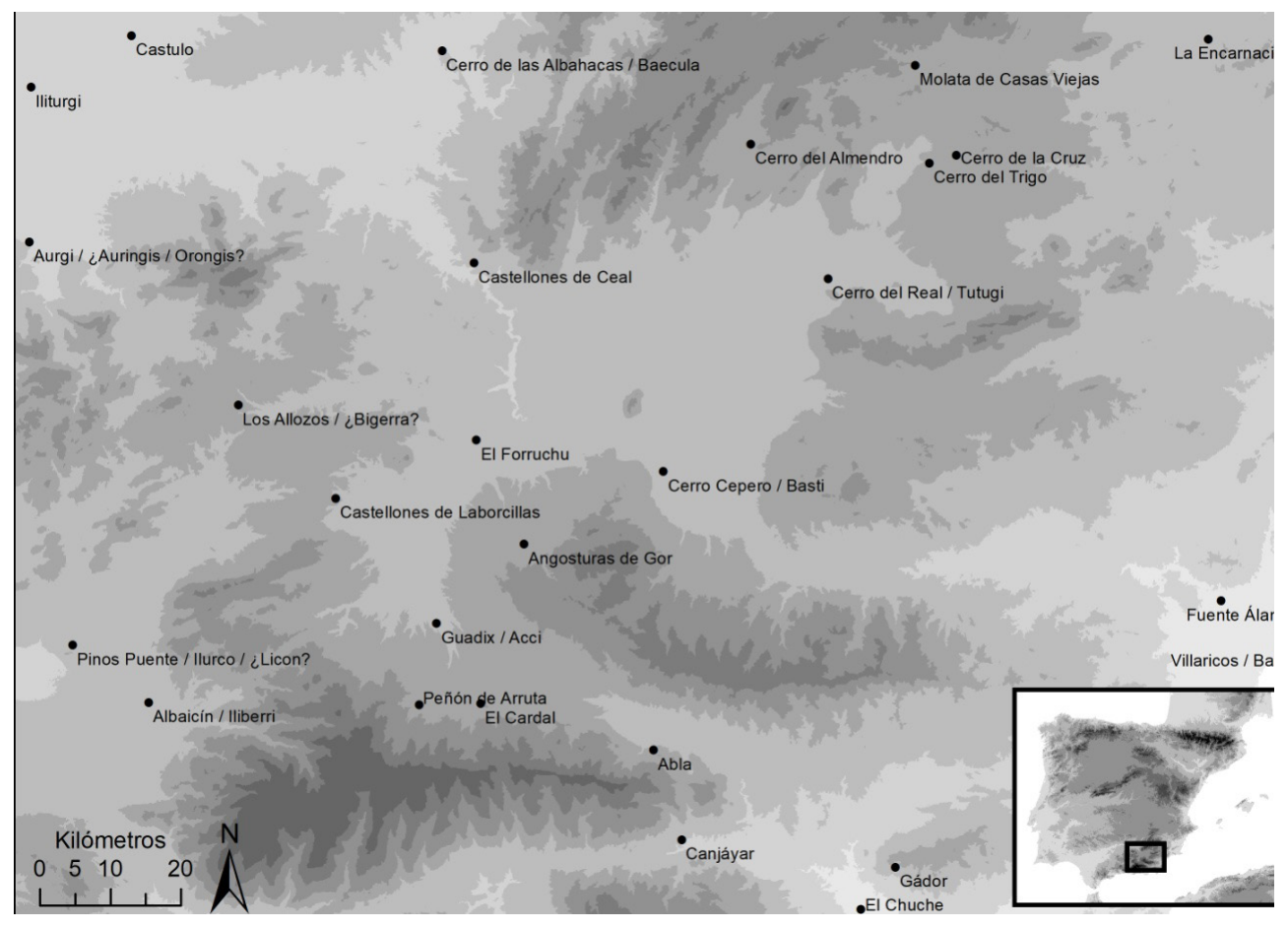

Fig. 2. Topónimos mencionados en el texto: Bastetania central y oriental (elaboración propia)

La guerra no regresaría a la Bastetania hasta varios años después. Hace casi medio siglo, R. Corzo propuso que, de camino a Baecula desde Tarraco, ${ }^{39}$ Publio Cornelio Escipión (el futuro Africano) pasaría por Carthago Nova y, por ende, hubo de atravesar en 208 a.C. las hoyas granadinas, dejando atrás ciudades tales como Basti o $A c c i .^{40}$ Resultaría lógico, en efecto, que, de camino hacia la Alta

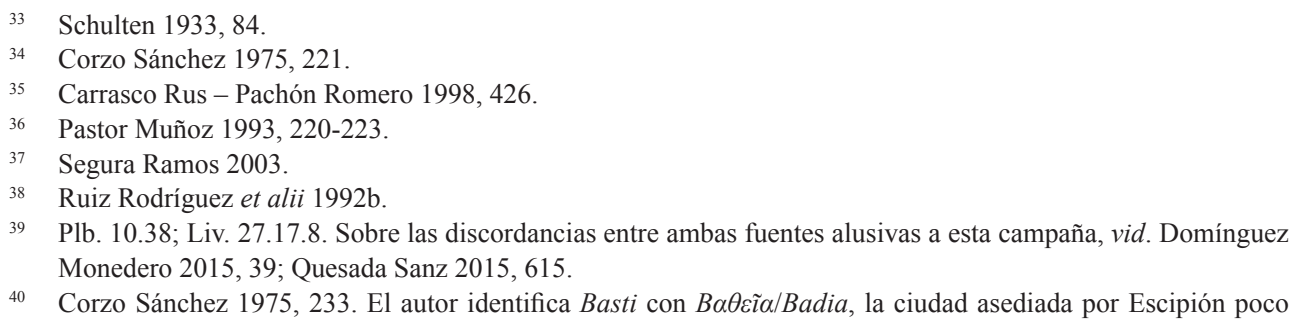


Andalucía y mientras iba reuniendo sus fuerzas a las de los aliados que le salían al paso, Escipión optara por reabastecer a sus tropas por mar en Carthago Nova y, de paso, asegurarse el control de la plaza recientemente tomada. ${ }^{41} \mathrm{~A}$ fin de cuentas, la internada de su padre y de su tío unos años antes a través del Saltus Castulonensis no había sido precisamente exitosa. Mas en los últimos tiempos la hipótesis de Corzo ha recibido un nuevo sostén de la mano de los colegas que han estudiado el campo de batalla próximo al Cerro de las Albahacas (Santo Tomé, Jaén), identificándolo verosímilmente con Baecula: el registro arqueológico de esta batalla demuestra que los romanos se aproximaron al escenario de la misma desde el sur, ${ }^{42}$ circunstancia que solo resultaría comprensible si accedieron a la región desde la Bastetania.

Apenas dirimida la batalla de Baecula, las armas romanas penetraron una vez más en la Bastetania. Tras su resonante victoria, Escipión, en vez de lanzarse en una persecución de Asdrúbal que se adivinaba infructuosa, dedicó lo que restaba de verano "a recibir la sumisión de los pueblos de Hispania". ${ }^{43}$ Es en este contexto en el que cabe situar la campaña de Lucio Cornelio Escipión, a quien su hermano, antes de regresar a Tarraco, dotó con 10.000 hombres y 1000 jinetes para asegurar las posiciones romanas en el sur. Según Livio, Lucio arremetió contra la rica ciudad de Orongis, "situada en el territorio de los meseses, rama de los bastetanos". ${ }^{44}$ La mayoría de los autores identifica Orongis con la Auringis citada por Livio en relación con la campaña del 212 a.C. y con la Aurgi mencionada en la epigrafía de la actual ciudad de Jaén, por lo que la consideración bastetana del enclave resulta problemática: circunstancia que no debe sorprendernos, pues deriva en realidad de la más que discutible restitución que del códice propuso A. Schulten, sustituyendo Hispanae gentis por Bastetanae gentis. ${ }^{45}$ Más claro en este sentido es Dion Casio, quien afirma taxativamente que Escipión encomendó a su hermano llevar la guerra a la Bastetania como parte de un plan global tendente a acabar con las bolsas periféricas de resistencia, en el marco del cual también se vieron afectados los territorios celtibéricos. ${ }^{46}$

Todo apunta, en fin, a que el objetivo principal de los romanos durante toda la guerra fue el de impedir que Aníbal recibiera refuerzos en Italia socavando las posiciones cartaginesas en el Levante, el valle del Guadalquivir, las estribaciones de Sierra Morena y la costa mediterránea, haciéndose presentes sobre el terreno a lo largo de las sucesivas campañas y apoyando activamente a las facciones prorromanas que pudieran surgir en muchas de las comunidades locales. El episodio de Bigerra y la campaña de Lucio Escipión, no obstante, resultan sumamente reveladores: aunque lejanas del frente y por lo general olvidadas por las crónicas, parece que las comunidades bastetanas participaron activamente en la guerra, viéndose transidas por toda una serie de tensiones, controversias, esfuerzos bélicos y conflictos intestinos propios de este tipo de coyunturas de retaguardia.

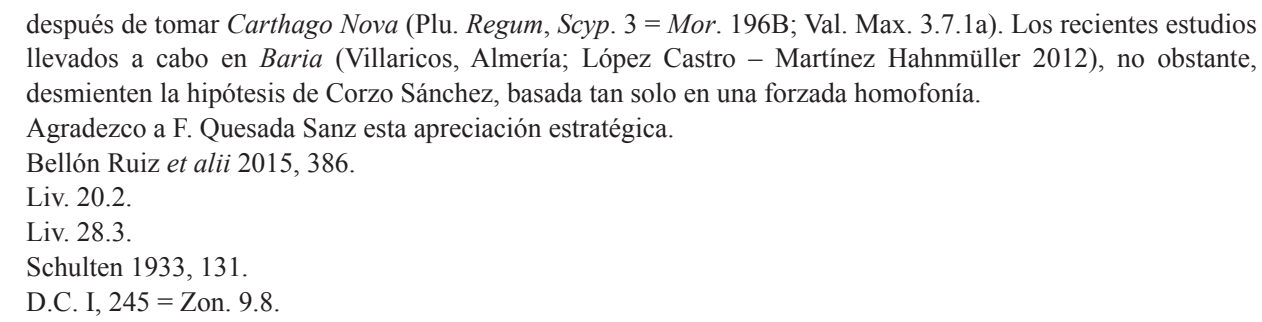

después de tomar Carthago Nova (Plu. Regum, Scyp. 3 = Mor. 196B; Val. Max. 3.7.1a). Los recientes estudios llevados a cabo en Baria (Villaricos, Almería; López Castro - Martínez Hahnmüller 2012), no obstante, desmienten la hipótesis de Corzo Sánchez, basada tan solo en una forzada homofonía.

Agradezco a F. Quesada Sanz esta apreciación estratégica.

Bellón Ruiz et alii 2015, 386.

Liv. 20.2.

Liv. 28.3.

Schulten 1933, 131.

D.C. I, $245=$ Zon. 9.8. 
Tras la evacuación y posterior derrota de Cartago, Roma quedó como potencia hegemónica en el territorio hispano. Dominaba militarmente toda la fachada mediterránea y el valle del Guadalquivir, pero entre una y otro prevalecía lo que I. Garcés denominó, muy acertadamente en nuestra opinión, un "enclave interior", ${ }^{47}$ los territorios bastetanos: todo un conjunto de sierras, altiplanos, hoyas y valles que habían quedado al margen de los ejes principales de la ofensiva escipiónica, y que, aunque inmediatos a las principales áreas de control romano, permanecieron relativamente ajenos a estas durante cierto tiempo. La ubicación de esta región montañosa, que en estos momentos coincidía con la difusa línea de demarcación que separaba ambas provinciae hispanas, ${ }^{48}$ y que por consiguiente la tornaba periférica respecto de ambas, seguramente coadyuvó también a este "desinterés" recíproco entre los agentes imperialistas romanos y las comunidades locales bastetanas.

Buena prueba de este alejamiento es la aparente no implicación de los bastetanos en el levantamiento de 197 a.C., una grave insurrección de numerosas comunidades hispanas contra el poder romano que exigió la llegada del cónsul Catón en 195 a.C., y que en el sur peninsular estuvo protagonizada por los régulos Luxinio y Culchas, al mando de muchas de las ciudades del valle del Guadalquivir y de los importantes puertos fenicios de Malaca y Sexi. ${ }^{49}$ Tras sofocar con crudeza la revuelta en el noreste, Catón descendió hacia el Guadalquivir, donde alcanzó toda una serie de acuerdos con los jerarcas locales que pusieron fin a la situación. Más allá de la posible datación en estos momentos de ciertos estratos de destrucción detectados en la periferia bastetana, ${ }^{50}$ y al margen de la discutible identificación de la ciudad de Turba (junto a la que el pretor Q. Minucio logró una victoria en 196 a.C. $)^{51}$ con la Turbula bastetana mencionada por Ptolomeo, ${ }^{52}$ repárese una vez más en el silencio que sobre las comunidades bastetanas mantienen las fuentes que narran el episodio, de lo más significativo dado que los territorios insurgentes rodeaban los altiplanos bastetanos. ${ }^{53}$

Roma no tardó en comprender el peligro que para la estabilidad del mediodía peninsular entrañaba la existencia del enclave bastetano, pero la concatenación de otros problemas más acuciantes en las demás fronteras hispanas y mediterráneas determinó que su definitiva conquista se ejecutara a través de toda una serie de campañas de alcance limitado e irregulares en el tiempo. Así, en 192 a.C., C. Flaminio, pretor de la Citerior, tomó al asalto Licabro $^{54}$ en una acción coordinada con la del procónsul a cargo de la Ulterior, M. Fulvio, quien conquistó las ciudades de Vescelia y Helo ${ }^{55}$ y

\footnotetext{
Garcés Estallo 2008.

Roldán Hervás - Wulff Alonso 2001, 107-108.

Liv. 33.21.6.

García Cano 2008, 119.

Liv. 33.44.4.

52 Aparte de lo endeble de la homofonía, Turba es solo una de las variantes recogidas por los códices, junto con Turda, preferida por Weissenborn y Müller (Weidmannsche Buchhandlung, Berlín, 1883). Vid. Pastor Muñoz 1993, 225.

53 Garcés Estallo 2008, 257-258.

54 Posiblemente identificable con la Igabrum epigráfica y, por ende, con la localidad cordobesa de Cabra (Segura Arista 1988).

55 Ya Thouvenot 1973, 110, identificó Vescelia con Vesci Faventia, ciudad bastetana según Plinio (HN 3.10) y túrdula para Ptolomeo (2.4.9), localizada seguramente entre las provincias de Málaga y Granada, acaso en Moraleda de Zafayona (García-Bellido - Blázquez Cerrato 2001, 403) o Archidona (Roldán Hervás - Wulff Alonso 2001, 110-111). Helo ha sido identificada de antiguo con Ilipula Laus, ciudad bastetana según Plinio (HN 3.10) pero de localización incierta.
} 
algunos otros fortines antes de proseguir campaña en la Oretania, alcanzando el valle del Tajo. ${ }^{56}$ Las depresiones cordobesas y el cauce medio del Genil, pues, comenzaban a caer bajo control romano, y los eventuales focos de oposición fueron suprimidos de manera sumaria. Tal fue el caso, posiblemente, del recinto fortificado del Cerro de la Merced (Cabra, Córdoba), una casa fuerte situada a apenas 5,5 km de Licabro-Cabra, coetánea a esta $\mathrm{y}$, acaso, ocupada por un señor de la guerra cuyos vínculos con el oppidum vecino resultan, por el momento, difíciles de discriminar. ${ }^{57}$ Según parece, el abandono súbito del recinto vino aparejado con la destrucción sistemática de sus fortificaciones, que entrañó, entre otras cosas, el socavado metódico de los ángulos de la edificación. Pues bien, a pesar de que el estudio de las recientes campañas de excavación todavía está en marcha, todo apunta a que la destrucción del complejo fortificado no tuvo lugar durante la primera mitad del siglo I a.C., como parecían sugerir los resultados preliminares, ${ }^{58}$ sino precisamente entre finales del siglo III y comienzos del II a.C. ${ }^{59} \mathrm{Su}$ final, por consiguiente, puede ser puesto en relación con la Segunda Guerra Púnica, o bien con esta política romana de progresiva "pacificación" de la periferia bastetana; en este sentido, la citada campaña de C. Flaminio contra la inmediata Licabro se postula como una opción muy a tener en cuenta.

Idéntica estrategia siguió L. Emilio Paulo durante la primera fase de su campaña de 190 a.C., cuando, según Livio, se internó al frente de sus legiones en la Bastetania pero fue derrotado frente a Licon, perdiendo 6000 hombres. ${ }^{60}$ Esta noticia resulta singular en varios aspectos: la derrota fue silenciada por Polibio y Plutarco (que señalan tan solo las grandes victorias del pretor en el valle del Guadalquivir), pero además se trata de la primera ocasión en la que las fuentes grecorromanas recogen el corónimo "Bastetania" y, asimismo, de la primera aparición de los lusitanos combatiendo contra Roma, llamativamente lejos de sus fronteras y en número suficiente como para infligir 6000 bajas a las legiones de Emilio Paulo. Para empeorar las cosas, no contamos con ninguna otra referencia de la ciudad de Licon. ${ }^{61}$ A resultas de todo ello, no han faltado los autores que han propuesto enmendar el texto del patavino, aduciendo que la derrota contra los lusitanos sería posterior a la incursión de L. Emilio en la Bastetania, ${ }^{62}$ trasladando toda la campaña al suroeste peninsular, ${ }^{63}$ o bien explicando que los lusitanos eran mercenarios de las ciudades bastetanas. ${ }^{64}$ En nuestra opinión, sin embargo, y como ya defendiera hace unos años I. Garcés, ${ }^{65}$ nada hay de especialmente problemático en el pasaje liviano: L. Emilio Paulo no hizo sino continuar con la estrategia romana inaugurada por L. Cornelio Escipión e impulsada nuevamente por M. Fulvio, tendente a conquistar militarmente el enclave bastetano (seguramente percibido

\footnotetext{
Liv. 35.22.5-6.

57 Quesada Sanz - Camacho Calderón 2014. Sobre la pertinencia del concepto "señor de la guerra" para este tipo de contextos asociados a los procesos de provincialización romana, vid. Naco del Hoyo - López Sánchez 2017. Quesada Sanz - Camacho Calderón 2014; Quesada Sanz et alii 2015.

F. Quesada Sanz, comunicación personal.

Liv. 37.46.7. Orosio añade erróneamente que el propio general murió en la batalla (Oros. 4.20.23).

61 Schulten 1933, 196-199, y Pastor Muñoz 1993, 225, la identifican con Ilugo (Santisteban del Puerto), aunque predomina la propuesta de Thouvenot 1973, 112, respecto de Ilurco (Pinos Puente, Granada), en cuyas cercanías aparece con frecuencia numerario cartaginés (Adroher Auroux et alii 2005, 81).

62 Thouvenot 1973, 112.

63 Pérez Vilatela 1989.

64 Chic García 1980.

65 Garcés Estallo 2008, 260-262.
} 
como tal por los propios romanos) ascendiendo por el valle del Genil; en cuanto a la presencia lusitana en la región, volvería a producirse en las décadas venideras, tal y como enseguida veremos y trataremos de explicar.

En efecto, la siguiente ocasión en la que Bastetania aparece en las crónicas de guerra lo hace en relación con las Guerras Lusitanas. Según Apiano, tras las derrotas sufridas ante Q. Fabio Máximo Emiliano en 144 a.C., Viriato optó por una estrategia más prudente con dos directrices básicas: soliviantar contra los romanos a las comunidades más proclives a ello (debido a su reciente conquista o a su situación periférica) y valerse de los territorios más agrestes para reagrupar fuerzas. ${ }^{66}$ En este contexto, no debe sorprender que los lusitanos cayeran sobre Ituca ${ }^{67} \mathrm{y}$, aprovechando esta cabeza de puente en el tan prorromano valle del Guadalquivir, se derramaran por la Bastetania. Mas, cuando en 141 a.C. Fabio Máximo Serviliano asumió el gobierno de la Ulterior, los romanos recuperaron la iniciativa: reconquistaron Ituca, pusieron en fuga a los lusitanos y saquearon cinco ciudades "que se habían puesto de parte de Viriato"; a continuación, y siguiendo los pasos de Viriato hacia el oeste, Serviliano tomó al asalto Escadia, Gemela y Obolcola, donde el lusitano había establecido guarniciones. ${ }^{68}$ Desconocemos el nombre de las cinco ciudades prolusitanas saqueadas, aunque por el contexto de la narración podría tratarse de comunidades bastetanas. Así parece sugerirlo la ubicación de los tres enclaves con guarniciones lusitanas asaltados después por los romanos mientras perseguían a Viriato, distribuidos en los límites occidentales de la Bastetania. En efecto, Escadia ha sido identificada por J. M. Campos y J. Bermejo ${ }^{69}$ con el municipio flavio de Nescania, sito en Valle de Abdalajís (Málaga), pero lo cierto es que tanto la toponimia árabe (Wasqa) como las dimensiones del caserío excavado y su ubicación, por no hablar de la cronología de su destrucción estrictamente coincidente con la campaña de Serviliano, podrían apuntar a su identificación con el Cerro de la Cruz de Almedinilla. ${ }^{70} \mathrm{El}$ topónimo Gemela es recurrente en los itinerarios, que en nuestro ámbito mencionan una mansio Ad Gemellas ${ }^{71}$ al sur de Benamejí (Córdoba). ${ }^{72}$ Obolcola, por último, se ubica en Fuentes de Andalucía (Sevilla).

En definitiva, todas estas peripecias nos hablan de unos momentos especialmente convulsos, en los que Roma ya controla militarmente la Bastetania, pero en los que las fidelidades a una u otra causa oscilan dependiendo de las coyunturas y las agendas de cada comunidad, cada grupo social y cada actor. Especialmente reveladoras en este sentido son las noticias referentes al discurso con el que Viriato arengó a los habitantes de Tucci para que se mantuvieran fieles a su causa ${ }^{73}$ o sobre la dureza de los castigos que Serviliano se vio obligado a prodigar contra las comunidades que habían faltado a sus obligaciones para con Roma ${ }^{74}$ palpables acaso, como veremos más adelante, en el registro arqueológico del Cerro de la Cruz de Almedinilla. No es

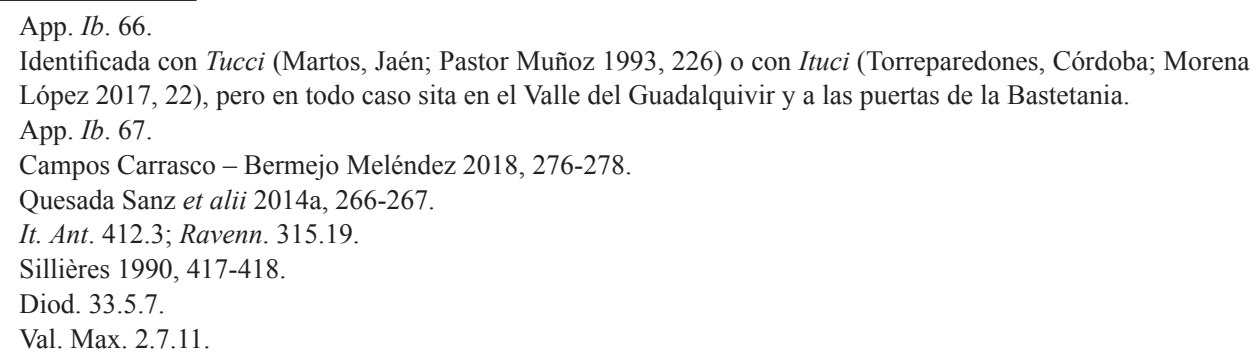


casualidad, pues, que el caudillo lusitano se abriera paso tan lejos de su tierra natal, atravesando todo el valle del Guadalquivir: con esta campaña, como quizás habían intentado hacer los lusitanos que vencieron a L. Emilio Paulo en 190 a.C., Viriato trató de abrir un nuevo frente contra Roma en una región agreste en la que el control romano todavía era precario.

Las comunidades bastetanas desaparecen por completo de nuestras crónicas tras las susodichas campañas viriáticas. Silencio este que no entraña necesariamente una ausencia total de conflictividad en las sierras del sureste hispano, como veremos, sino tan solo el desinterés de nuestros informantes antiguos, motivado por un desplazamiento de los principales frentes de guerra hacia el oeste y el norte.

\section{La transformación del territorio bastetano}

Como era de esperar, las transformaciones en los patrones de poblamiento y explotación del territorio estudiado reflejan solo parcialmente, y a menudo de manera indirecta, los acontecimientos narrados por las fuentes escritas. En este sentido, resulta llamativa la perdurabilidad general durante toda la primera mitad del siglo II a.C. de las dinámicas de poblamiento que ya estaban activas en el siglo III a.C. y que, tras la conquista romana de la región, tardarán, como veremos enseguida, en verse afectadas de manera significativa. Se produjeron, bien es cierto, algunos casos episódicos pero esperables de destrucciones y abandonos posiblemente relacionados con la Segunda Guerra Púnica. Tal es el caso del mal conocido asentamiento de Los Allozos, ${ }^{75}$ o del coetáneo nivel de incendio documentado en el Cerro de la Mora (Moraleda de Zafayona, Granada), ${ }^{76}$ situados ambos, no por casualidad, en los límites de la Bastetania con el Alto Guadalquivir y con el Bajo Genil respectivamente, zonas ambas en las que las crónicas de guerra recogen fuertes combates durante las diversas fases del conflicto. ${ }^{77}$

Así las cosas, podemos considerar que la estructura de poblamiento de los valles bastetanos durante las primeras décadas del siglo II a.C. fue heredera en líneas generales de las dinámicas que ya llevaban activas desde, al menos, comienzos del siglo III a.C. El territorio estaba nuclearizado en torno a toda una serie de oppida, separados entre sí unos $30 \mathrm{~km}$ de media y cuya historia por lo general se retrotraía varios siglos en el tiempo, tales como Cerro de las Cabezas (Fuente Tójar, Córdoba), Pinos Puente (Granada), Albaicín (Granada), Guadix (Granada), El Forruchu (Villanueva de las Torres, Granada), Cerro Cepero (Baza, Granada), Cerro del Real (Galera, Granada) o Molata de Casa Vieja (Puebla de Don Fadrique, Granada). ${ }^{78}$ La magnitud de estos núcleos rectores de primer orden, en cualquier caso, parece ser significativamente menor que la de los oppida coetáneos del valle del Guadalquivir, la Baja Andalucía o el Sureste. ${ }^{79}$ A partir del siglo III a.C., no obstante, debido

\footnotetext{
Pachón Romero et alii 2004.

Adroher Auroux et alii 2002, 93.

7 Sin pretender excedernos en la interpretación, recordaremos tan solo que la ciudad de Bigerra, cuyo asedio cartaginés desbarataron los Escipiones en 214 a.C., ha sido ubicada en el entorno de Los Allozos, y que desde Bigerra hasta el Bajo Genil, donde se libró la subsiguiente batalla de Munda, las legiones romanas hubieron de transitar junto al Cerro de la Mora (Corzo Sánchez 1975, 221).

78 Mayoral 2004, 213-214; Adroher Auroux 2008, 215; Zamora 2010, 62.

79 González Román 1992, 158; Gozalbes Cravioto 2000, 43; Adroher Auroux - López Marcos 2002, 11-17.
} 
posiblemente a toda una serie de dinámicas socioeconómicas internas, todos estos oppida impulsaron una colonización más extensiva del territorio, creando pequeños asentamientos fortificados subsidiarios en entornos de potencial agrológico limitado pero controlando los principales pasos $;{ }^{80}$ asimismo, se promovió la fundación de asentamientos rurales en llanura de clara vocación agropecuaria y de pequeños poblados fortificados destinados a potenciar la producción minerometalúrgica. ${ }^{81}$

Merece la pena hacer dos breves puntualizaciones en relación con este proceso colonizador del entorno territorial de los oppida. Repárese, en primer lugar, en que hablamos tan solo de tendencias generales, pero de ningún modo de un proceso homogéneo: obsérvese, por ejemplo, que ciertas comarcas, como la Hoya de Baza, llegaron a contar con un poblamiento relativamente denso, ${ }^{82}$ mientras que otras, como el suroeste de la provincia granadina, permanecieron casi despobladas hasta época altoimperial. ${ }^{83}$

Y, en segundo lugar, recordemos que hablamos de un proceso heredado del siglo III a.C. (es más, activo seguramente desde el siglo V a.C.) y que durante la primera media centuria de presencia romana en el entorno no hizo sino continuar. Bien es cierto que en algunas de las fortificaciones levantadas para defender las vías de comunicación o para dinamizar los entornos mineros se documentaron pavimentos de opus signinum, proporciones más elevadas de vajilla de mesa mediterránea o incluso murallas con rasgos arquitectónicos alóctonos, pero ello no debe llevarnos a asumir, como en ocasiones se ha hecho, ${ }^{84}$ que se trataba de asentamientos levantados por iniciativa romana, o al menos con una presencia romana muy marcada; antes bien, como defendiera en su momento V. Mayoral, ${ }^{85}$ hablamos de la materialización en el territorio de unas elites locales que buscaban diversificar y potenciar la obtención de recursos de sus respectivas comunidades, que estaban presentes en estos nuevos núcleos rurales, y que los aprovechaban para exhibir sus programas ideológicos y sus discursos de poder, cada vez más cargados de matices helenísticos. No es casualidad que en el entorno de estas elites locales bastetanas de la primera mitad del siglo II a.C. no solo aparezcan elementos de marcada raigambre itálica; los aljibes a bagnarola documentados en el Cerro de la Cruz de Almedinilla y en el Albaicín nos indican, ${ }^{86}$ en efecto, que el modelo a seguir para estas elites no era forzosamente romano ( $\mathrm{si}$ es que existía un modelo puramente "romano" en la época), sino helenístico y seguramente púnico.

Curiosamente, fue durante la segunda mitad del siglo II a.C. cuando comenzaron a observarse transformaciones apreciables en las dinámicas de poblamiento de los valles y hoyas bastetanos. La gran mayoría de los oppida de la región continuaron poblados durante siglos, siendo promocionados a municipios o colonias a finales de la República

80 Tal es el caso del Cerro de la Cruz de Almedinilla (Córdoba), de los Castellones de Laborcillas (Morelabor, Granada), de las Angosturas de Gor (Granada), de los Castellones de Ceal (Hinojares, Jaén), del Cerro del Almendro (Huéscar, Granada); del Cerro de la Cruz (Puebla de Don Fadrique, Granada), de Fuente Álamo (Cuevas de Almanzora, Almería), de Abla (Almería), o de El Chuche (Benahadux, Almería): Adroher Auroux López Marcos 2002, 11-17; Zamora 2010, 62; Quesada Sanz et alii 2014a, 233-239; 2014b.

81 Adroher Auroux - López Marcos 2002, 11-21; Mayoral 2004, 161-162; Adroher Auroux 2008, 220-222; Zamora 2010, 56.

82 Caballero Cobos 2008, 310-312.

83 Pachón Romero 2008, 248.

84 Vid., por ejemplo, González Román et alii 1997; 2001.

85 Mayoral Herrera 2004, 213-214.

86 Cerro de la Cruz: Quesada Sanz et alii 2010, 85; Albaicín: Lozano Rodríguez et alii 2008. 
o bien convirtiéndose en municipia de derecho latino en tiempos de Vespasiano. Otro tanto sucedió con los pequeños asentamientos rurales de vocación agropecuaria o minerometalúrgica, que en líneas generales no desaparecieron hasta, cuando menos, el siglo I d.C. Por el contrario, los asentamientos fortificados secundarios -la mayor parte de los cuales, recordemos, se habían creado entre el siglo III y comienzos del II a.C. a impulsos de los oppida para reforzar el control del territorio y las vías de comunicación- tendieron a desaparecer a lo largo de esta última etapa ${ }^{87}$

Ahora bien, todo este proceso de transformaciones fue lo suficientemente complejo como para que merezca la pena observar con mayor detenimiento sus variantes comarcales. Así, en la depresión Priego-Alcaudete podemos observar que los tres oppida locales prosperaron, convirtiéndose en época flavia en municipia de derecho latino: La Almanzora-Sosontigi (Luque, Córdoba), Cerro de las Cabezas-Iliturgicola (Fuente Tójar, Córdoba) y Cerro del Castillo-Ipolcobulcula (Carcabuey, Córdoba). ${ }^{88}$ No parece casualidad que los tres se situaran en las inmediaciones del ramal de la vía Corduba-Iliberri que se internaba en esta comarca y que, en época romana, constituía la principal vía de comunicaciones de la misma. También pervivieron los asentamientos rurales de vocación agropecuaria, como Los Zurriones o Llanos de Zamoranos (ambos en Priego, Córdoba), así como algunos de los asentamientos fortificados de menor entidad, como Cerro del Puerto (Priego, Córdoba). ${ }^{89}$

No corrió la misma suerte, sin embargo, el poblado fortificado que mejor conocemos en la región, el ya citado Cerro de la Cruz de Almedinilla. Las recientes excavaciones efectuadas en el yacimiento han permitido corroborar su final violento, documentando un potente estrato de artefactos de toda índole completos y abandonados precipitadamente in situ antes de que los muros se vinieran abajo, así como los restos de seis seres humanos, al menos una parte de los cuales fue asesinada mediante armas blancas. El hasta entonces próspero hábitat quedó abandonado por completo, sin que se detecte ningún intento subsiguiente de volver a poner en pie ninguna de sus construcciones. Es más, todos los datos, desde el tipo de heridas detectadas sobre los cadáveres hasta la magnitud de la destrucción y lo repentino e irreversible del abandono, hacen pensar en una acción punitiva (ejecutada, por cierto, con armas identificables con gladii hispanienses). Una masacre que sus excavadores vinculan, a juzgar por la cronología del repertorio material estudiado y por la deriva de los sucesos en el marco regional, con las represalias que Serviliano tomó en 141 a.C. contra aquellas ciudades de la Bastetania que habían albergado guarniciones lusitanas, incluyendo la mencionada Escadia $9{ }^{90}$ extraordinariamente duras, a juicio de Valerio Máximo. ${ }^{91}$

En los valles centrales del territorio estudiado, esto es, en las cuencas del alto Genil y el Guadiana Menor, la perduración de las dinámicas de poblamiento a lo largo del período estudiado muestran muy pocas salvedades. Así, en la Vega de Granada, el otrora oppidum nuclear del Cerro de la Mora, cuya decadencia se había iniciado ya desde el siglo $\mathrm{V}$ a.C., se convirtió paulatinamente en un asentamiento rural de segundo orden, dependiente seguramente de Pinos Puente-Ilurco. ${ }^{92}$ De la urbanística

\footnotetext{
Adroher Auroux 2008, 222-225.

Vaquerizo Gil et alii 2001, 300.

Vaquerizo Gil et alii 2001, 296-299.

Quesada Sanz et alii 2014.

Val. Max. 2.7.11.

Román Punzón 2009.
} 
de Ilurco no es mucho lo que sabemos, pero la perduración del antiguo poblado ibérico hasta el siglo III d.C. parece fuera de toda duda, así como su identificación con la ceca que emitió moneda de bronce a mediados del siglo II a.C. y con el municipio latino promocionado en época flavia. ${ }^{93}$ Asimismo, el asentamiento del Albaicín-Iliberri prosperó durante la fase iberorromana, atrayendo un importante flujo de importaciones mediterráneas, albergando entre los siglos II-I a.C. una ceca e impulsando la fundación de pequeños asentamientos agrícolas y fortines secundarios para la defensa del territorio. Sus remodelaciones arquitectónicas, no obstante, fueron mínimas hasta mediados del siglo I a.C., conservándose incluso la muralla del siglo VI a.C..$^{94}$

Dinámicas similares se observan en los otros oppida nucleares de la región. En Guadix-Acci, conocemos mucho peor la fase ibérica tardía que las anteriores, pero la continuidad de la ciudad hasta época imperial romana viene asegurada por su deducción colonial en época cesariana o augustea, promoción que encuentra su correlato arqueológico en la remodelación urbana del enclave con la construcción de un gran criptopórtico. ${ }^{95}$ La prosperidad de los recursos minerometalúrgicos del territorio accitano, y de los enclaves secundarios especializados en su obtención y transformación, sin duda tuvo mucho que ver en esta singular deducción colonial, la única del entorno. En la Hoya de Baza, Cerro Cepero-Basti continúa poblado y prosigue implementando la creación de pequeños hábitats rurales de vocación agrícola en su entorno inmediato, aunque no experimentará una remodelación arquitectónica significativa hasta época augustea, cuando con toda probabilidad se produce además la centuriación de los territorios aledaños. ${ }^{96}$ En la depresión de Huéscar, finalmente, tanto el oppidum del Cerro del Real-Tutugi como las pequeñas alquerías rurales de sus inmediaciones perviven hasta más allá del cambio de Era, e incluso el primero se convierte en municipio de derecho latino en época flavia. No sucede lo mismo, en cambio, con el otro oppidum nuclear de la región, el Forruchu, abandonado a mediados del siglo I a.C., ${ }^{97}$ ni tampoco con esos otros asentamientos fortificados de segundo nivel que aseguraban las comunicaciones intercomarcales, como Castellones de Ceal, Castellones de Laborcillas o Angosturas de Gor, abandonados todos ellos en torno al siglo I a.C..$^{98}$

En el campo de Bugéjar, por su parte, encontramos la transformación socioespacial más traumática de toda la Bastetania, acaecida en el último cuarto del siglo II a.C. En efecto, en estas fechas se abandona el que hasta entonces había sido el oppidum nuclear de la comarca, Molata de Casa Vieja, y quizás también los dos núcleos fortificados secundarios que controlaban la periferia de aquel, Cerro de la Cruz y Cerro del Almendro (en estos dos últimos, de hecho, se detectan indicios de niveles de destrucción), así como algunos de los pequeños hábitats rurales dependientes. En su lugar, se estableció un gran campamento militar romano, el Cerro del Trigo, que durante dos generaciones articularía el poblamiento rural disperso que en lo sucesivo caracterizará a la comarca. Entre las alquerías creadas en estos momentos, por cierto, merece la pena destacar el Cortijo del Duque, un hábitat rural creado ex novo sobre

\footnotetext{
Morales Rodríguez - Castillo Rueda 2009.

Adroher Auroux et alii 2005, 79-83; Sánchez Moreno 2015, 520.

López Marcos 2008.

Caballero Cobos 2008.

Adroher Auroux 2008, 222.

Chapa Brunet et alii 1999; Adroher Auroux - López Marcos 2002, 11-17.
} 
lo que hasta entonces había sido una de las necrópolis del Cerro de la Cruz, que evidentemente quedó desacralizada y amortizada. ${ }^{99}$

En lo que respecta a la explotación de los recursos naturales del territorio, ítem más, observamos igualmente un marcado continuismo hasta bien entrado el siglo I a.C., apenas connotado con ciertos elementos exógenos esperables en una coyuntura histórica como la que tratamos. Para empezar, y a diferencia de lo ocurrido en otras regiones hispanas, los datos disponibles no avalan una colonización itálica del agro bastetano. Las formas de propiedad no parecen variar de manera sustancial y, aun cuando algunos autores creen apreciar signos en el territorio de cierta conflictividad agraria, esta parece derivar de las dinámicas internas propias de un medio rural sometido a la creciente exacción fiscal romana, y no tanto de unas transformaciones en los modos de producción que todavía no se aprecian. ${ }^{100}$ Significativamente, será en los espacios apenas explotados de manera intensiva en época ibérica, como la Vega de Granada, donde proliferen primero y con más intensidad las villae romanas. ${ }^{101}$ En cambio, en el bien estudiado entorno de Basti las pequeñas explotaciones agrarias creadas entre los siglos III y II a.C. pervivirán hasta época imperial sin apenas transformaciones y sin que sobre ellas se instalen nuevas unidades de explotación del tipo villa. ${ }^{102}$ Estas dinámicas continuaron vigentes hasta época augustea, momento en el que se advierte una reorganización parcelaria del territorio que entraña la ocupación extensiva y puesta en explotación de las tierras cultivables alejadas de los ríos y, con toda probabilidad, un viraje en las dinámicas económicas locales y, posiblemente, en las formas de propiedad. ${ }^{103}$ También en el entorno de Acci se han detectado trazas de una posible centuriación, ${ }^{104}$ que sin duda habría que vincular a la promoción colonial del enclave en las últimas décadas del siglo I a.C.

La extracción minera de la región parece seguir idénticos derroteros. En este sentido, merece la pena centrarnos en la comarca de Guadix donde, a la altura del siglo III a.C., se levantó El Cardal (Ferreira, Granada), un pequeño asentamiento fortificado rodeado por un muro doble y que cobijaba tan solo un puñado de viviendas, claramente orientadas a la producción y procesamiento mineralometalúrgicos. ${ }^{105}$ El asentamiento se abandonó a finales del siglo II o comienzos del I a.C., por lo que durante un tiempo coexistió con el cercano poblado fortificado del Peñón de Arruta (Jérez del Marquesado, Granada), frecuentado ya durante el Ibérico Pleno pero cuya fase de ocupación mejor conocida arranca en el tercer cuarto del siglo II a.C. y se prolonga durante solo una centuria. ${ }^{106}$ Las características técnicas de la muralla de este último hábitat, a piedra seca, con paramentos a plomada y torres rectangulares proyectadas hacia el exterior y con cámaras internas, muestran una clara cesura respecto de la arquitectura defensiva de la región en épocas previas, lo que llevó a sus excavadores a identificarlo como un fortín romano encargado de

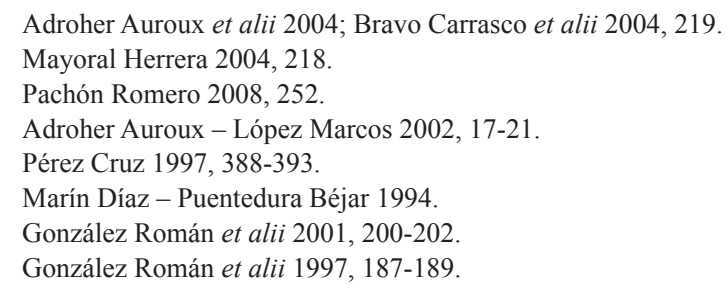


supervisar la producción local de hierro, ${ }^{107}$ de la misma manera que, según ellos, una guarnición romana habría empleado hasta entonces con idéntico propósito la fortaleza "indígena" de El Cardal. ${ }^{108}$

Por nuestra parte, sin embargo, nos permitimos discrepar de esta lectura. Quisiéramos dejar abierta siquiera la posibilidad de que tanto la factoría de El Cardal como la del Peñón de Arruta respondieran al progresivo proceso de colonización e intensificación de la explotación de sus territorios orquestada desde el oppidum de Guadix y, de hecho, no debemos olvidar que ambos estaban ya habitados antes de la conquista romana. Si bien es cierto que en su última fase constructiva las fortificaciones del Peñón de Arruta responden a una edilicia marcadamente romana, esta, creemos, resulta coherente con la coyuntura histórica de finales del siglo II a.C. en la que se erige, y en ningún caso resultaría significativa por sí misma de la identidad étnica de sus habitantes. Más indicativa en este sentido sería la continuidad general en el modelo de poblamiento y en los sistemas extractivos, sin ruptura aparente hasta, como ya dijimos, las últimas décadas del siglo I a.C. Repárese también en que el registro cerámico detectado (bien es cierto que recogido en superficie) no difiere del de los hábitats vecinos, abundante en platos de borde recto divergente, platos de borde vuelto y cuencos de tradición ibérica, a los que se añaden cuatro fragmentos de ánforas Dressel 1 A, un fragmento de Campaniense B y algunos fragmentos de cerámica de paredes finas sin engobe. ${ }^{109}$

En todo caso, seguramente no sea casual que el abandono del Peñón de Arruta coincida con la promoción colonial de Acci y con la centuriación de su entorno: el cambio en la estructura de la propiedad y el estatuto jurídico del núcleo rector dio pie a una transformación profunda de las dinámicas económicas de su entorno.

Dinámicas parecidas acusa, de hecho, la extracción de oro en la región. Aunque Estrabón certifica que la Bastetania era pródiga en oro, ${ }^{110} \mathrm{y}$ aunque de hecho sabemos que alberga varios yacimientos auríferos aluviales, no tenemos constancia de que los mismos fueran explotados por las comunidades locales antes de la época augustea. ${ }^{111}$ Es solo a partir del advenimiento del Imperio cuando comenzarán a proliferar las estructuras relacionadas con la actividad extractiva, tales como las identificadas en el Hoyo de la Campana (Granada) o en las Hoyas del Tullido (Caniles, Granada), vinculables a los municipia de Iliberri y Basti, respectivamente. ${ }^{12}$

Como argumento suplementario para avalar la autoridad romana sobre las actividades extractivas del Peñón de Arruta y su supuesto carácter militar, sus excavadores aluden a un asa poligeminada de tradición ibérica hallada en el yacimiento sobre la que se atestiguó un grafito con tres letras capitales actuarias: [- - - ]REX[- - - ]. ${ }^{113}$ Según los susodichos autores, este grafito puede ponerse en relación con las marcas documentadas en varios galápagos de plomo de Canjáyar (Almería) en las que se alude a $L . S$. Rex. ${ }^{114}$ La reiteración de este cognomen

\footnotetext{
González Román et alii 1997, 191-192.

González Román et alii 2001, 210.

109 Gonzalez Román et alii 1997, 187-188.

10 Str. 3.4.2.

111 Domergue 1990, 170.

112 García Pulido 2014, 68-105 y 234-248.

113 González Román et alii 1997, 189-190, n 27, de donde HEp 7, 1997, 342 (en su comentario a este registro, no obstante, A. Canto lee $+E X \cdot X$, considerando que pudiera tratarse de una señal de recuento).

114 CIL II 4964 y 6247.7.
} 
latino en relación con las minas estaría hablando según ellos de la presencia de un publicano, quizás a la cabeza de toda una societas, que en algún momento habría controlado la producción minera de la región. ${ }^{115}$ Esta conclusión, no obstante, nos parece matizable: aun aceptando la supuesta coincidencia del cognomen (dada la fragmentación del asa poligeminada, su lectura no es segura), esta tan solo avalaría la presencia sobre el terreno de un privatus o de una societas vinculada a las actividades extractivas, pero no necesariamente que las mismas se estuvieran llevando a cabo por cuenta de la autoridad romana y bajo custodia militar. Recuérdese que, también en el siglo II a.C., los negotiatores romanos hacían fortuna incluso en los territorios no sometidos todavía a la jurisdicción romana, como Asia Menor, Grecia, Cartago o Numidia. ${ }^{116}$ Y repárese a este respecto en el otro documento epigráfico mencionado también por los antedichos autores, el llamado plomo de Gádor (El Barranco del Rey, Almería): una inscripción sobre plomo en escritura ibérica levantina hallada en el interior de una mina de galena argentífera y datable en la segunda mitad del siglo II a.C., en la que al parecer se recoge un registro de contabilidad o un protocolo comercial. ${ }^{117} \mathrm{Y}$ es que, salvo en ciertos contextos fuertemente represaliados por cuestiones políticas como Carthago Nova, lo que parece imperar en los circuitos económicos de la Hispania de los siglos II y I a.C., Bastetania incluida, fue la asociación y colaboración entre los agentes itálicos, los agentes hispanos y las autoridades locales. ${ }^{118}$ No se olvide a este respecto que, en un pasaje al que la historiografía no ha prestado demasiada atención, Estrabón afirmaba que, a diferencia de las minas de oro, los yacimientos argentíferos en torno a Carthago Nova no eran de propiedad estatal, sino particular. ${ }^{119}$ En efecto, la arqueología parece demostrar que, hasta época muy tardía, esas mismas minas no fueron explotadas por grandes societates esclavistas, sino por pequeños núcleos particulares apegados al sistema productivo tradicional ibérico. ${ }^{120}$

En cuanto a la producción y circulación monetaria, llama la atención que, a diferencia de las regiones aledañas, no parece que la Bastetania contara con una economía de base monetaria hasta un momento muy tardío. Tan solo podemos situar con seguridad dos cecas en territorio bastetano que acuñaran antes del principado de Augusto, Ilurco e Iliberri, y ninguna de las dos fue demasiado prolífica: la primera emitió una única serie en bronce durante la primera mitad del siglo II a.C., con cabeza masculina a la derecha tanto en anverso como en reverso y la leyenda latina ILVRCON; ${ }^{121}$ la segunda, en cambio, acuñó cuatro series de cronología discontinua: la primera con leyenda latina FLORENTIA, durante los últimos años del siglo III a.C. o la primera mitad del siglo II a.C., y las otras tres, llamativamente con leyendas ibéricas ilturir, durante la segunda mitad del siglo II a.C. ${ }^{122}$ También podría encuadrarse en el territorio bastetano la ceca púnica de ' $l b t$, si es que es correcta su identificación

\footnotetext{
115 González Román et alii 1997, 187-189; Padilla Arroba 2016, 112.

116 Larissa: Arch. Eph. (1910), 344-349; Cirta: Sall. Iug. 21.2; 26; Diod. 34-35; Cartago: Plb. 36.7.5; App. Afr. 92. Vid. Roselaard 2012.

117 Untermann, $M L H$ III, 2, 640-642.

118 Díaz Ariño 2009.

119 Str. 3.2.10.

120 García Cardiel 2016, 78-79.

121 García-Bellido - Blázquez Cerrato 2001, 198-199.

122 García-Bellido - Blázquez Cerrato 2001, 177-178; Ruiz López 2011.
} 
con la $\mathrm{A} \beta \mathrm{ov} \lambda \alpha$ mencionada por Ptolomeo ${ }^{123}$ y con la Alba situada por el Itinerario Antonino entre Urci y Acci, ${ }^{124}$ pero en todo caso su única serie parece muy tardía, seguramente del siglo I a.C., y responde a patrones metrológicos, lingüísticos y tipográficos análogos a los de las ciudades feniciopúnicas costeras. ${ }^{125}$ Asimismo, Acci solo comienza a acuñar moneda tras su promoción colonial en época augustea. ${ }^{126}$ Otro tanto sucede con los ocultamientos de moneda: de los treinta y siete tesorillos documentados en el sur peninsular y datables en el siglo II a.C., ${ }^{127}$ solo tres aparecen en la Bastetania, todos ellos fechables a finales de siglo y asociados a contextos mineros: Orce, Cogollos de Guadix y Guadix. ${ }^{128}$

Dedicaremos, finalmente, unas breves palabras a los circuitos comerciales que irrigaron la Bastetania entre los siglos II y I a.C. Pese al singular tradicionalismo del repertorio cerámico de la región, sobre el que más tarde volveremos, las importaciones itálicas no tardaron en hacerse presentes en una parte de los valles bastetanos, fluyendo seguramente a través de los mismos circuitos comerciales que llevaban conectando la región con el Mediterráneo durante siglos. De este modo, los vasos de Campaniense $\mathrm{A}$, los barnices rojos pompeyanos y las ánforas grecoitálicas se detectan desde finales del siglo III a.C. en ciertos enclaves nodales bien comunicados de la Bastetania central y oriental, como Iliturgi o Basti, ${ }^{129}$ pero no aparecen en otros más occidentales destruidos por esas mismas fechas, como el Cerro de la Merced, $\mathrm{y}$ apenas lo hacen en un asentamiento fortificado secundario destruido a mediados del siglo II a.C., como el Cerro de la Cruz de Almedinilla, pese a que la magnitud del descalabro de este último nos garantiza la integridad de la muestra recuperada. ${ }^{130}$ Hasta el último cuarto del siglo II a.C., de hecho, las importaciones itálicas no se derraman de manera generalizada por la Bastetania ${ }^{131}$ evidenciando por consiguiente un considerable retardo respecto de las regiones adyacentes.

El verdadero vuelco en los circuitos comerciales bastetanos se produjo hacia el cambio de Era, y no antes. El acondicionamiento y potenciación de la Vía Augusta, que recorría la costa mediterránea hasta Carthago Nova para después virar hacia el interior andaluz por la zona de Chirivel, tornó obsoleta la antigua conexión entre los altiplanos murcianos de Caravaca y la comarca de Puebla de Don Fadrique, ${ }^{132}$ quedando estos dos últimos espacios abocados a la desestructuración territorial y a una nueva configuración rural, de la que el abandono del Cerro del Trigo, el establecimiento militar que durante el último siglo había nuclearizado el poblamiento en la zona, da buen testimonio. ${ }^{133}$ En cambio, la reactivación de la comarca de los Vélez en estas mismas épocas parece evidente. ${ }^{134}$

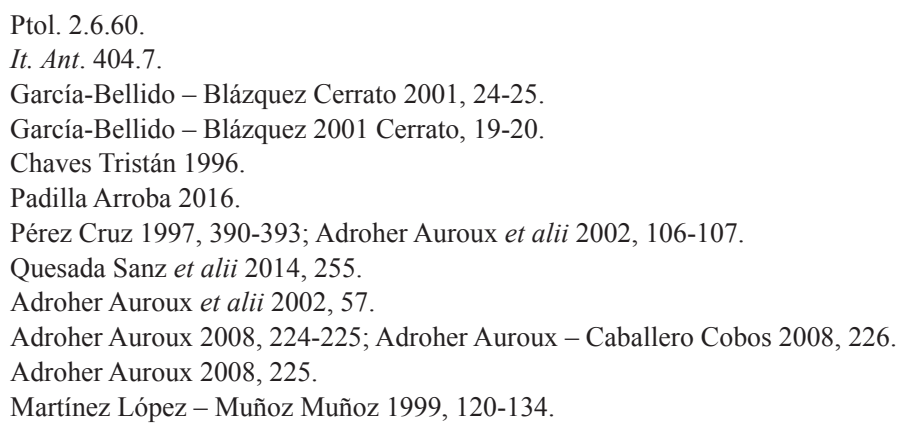




\section{Los discursos ideológicos}

A lo largo de las páginas previas ya hemos mencionado en varias ocasiones el particular tradicionalismo de la tipología cerámica bastetana entre los siglos II y I a.C. ${ }^{135}$ Pese a que las importaciones mediterráneas comenzaron a llegar a la Bastetania central a finales del siglo III a.C., pese a la introducción de elementos de prestigio como ciertas técnicas arquitectónicas y pese a la presencia de romanos e itálicos en los valles bastetanos atestiguada por las fuentes literarias y por la epigrafía, las comunidades locales de la región se mostraron en buena medida refractarias a renunciar a sus vasos de almacenaje y su vajilla de mesa tradicionales. Tradicionalismo este, por consiguiente, que solo cabe explicar por cuestiones ideológicas, pero que no forzosamente ha de contemplarse como la materialización de una pertinaz resistencia étnica al invasor romano, como en ocasiones, ya lo dijimos, se viene proponiendo.

$\mathrm{Y}$ es que en los valles y altiplanos bastetanos detectamos ciertos discursos ideológicos que, aunque nunca llegaron a difundirse por la totalidad de nuestra zona de estudio, plantean discontinuidades significativas respecto de las regiones vecinas, lo que contribuye, creemos, a reforzar la singularidad de la región bastetana durante los siglos II y I a.C. y, por ende, su interpretación como "enclave". Repárese, por cierto, en que no hablamos simplemente de particularismos culturales, sino de discursos ideológicos propiamente dichos, esto es, de discursos edificados y difundidos por las elites locales para construir, materializar y naturalizar su poder, y que como mínimo fueron aceptados parcialmente y reinterpretados por una parte significativa de la población. ${ }^{136}$ Unos discursos que, en su singularidad, sugieren que las elites bastetanas experimentaron durante los siglos II y I a.C. necesidades y estímulos distintos de los de sus homólogas de las regiones aledañas, o que al menos buscaron referentes ideológicos diversos desde los que construir su poder.

Así parece poder colegirse del aparente abandono de las necrópolis. Es llamativa la escasez de enterramientos datables entre los siglos II y I a.C., ${ }^{137}$ lo que, según se pensó en su momento, conectaría la Bastetania con el área turdetana, donde este registro igualmente se creía que brillaba por su ausencia (tesis paulatinamente desacreditada a medida que se han ido sucediendo los hallazgos, el último de los cuales ha sido el depósito del carro de Montemayor). ${ }^{138}$ Ahora bien, todo apunta a que los cambios que, en efecto, se perciben en el registro funerario bastetano responden a las dinámicas poblacionales activas desde siglos atrás, y no tanto a una supuesta ruptura provocada por la llegada de Roma. Así, por ejemplo, en las inmediaciones de Baza la necrópolis del Cerro del Santuario se había abandonado ya en el siglo IV a.C., pero tanto la de Cerro Largo como la de Las Viñas parecen mantenerse en uso sin solución de continuidad hasta el siglo II a.C. ${ }^{139}$ Bien es cierto que carecemos de datos sobre los enterramientos del siglo I a.C., pero admitamos que tampoco es mucho lo que conocemos sobre el núcleo habitado en esos mismos años. También la necrópolis del Cerro de la Cruz de Almedinilla, ya en uso desde época Ibérica Plena,

\footnotetext{
135 Vaquerizo Gil et alii 1994, 62.

136 García Cardiel 2016, 24-29.

137 Adroher Auroux - López Marcos 2002, 21-23.

138 Sobre la presencia de contextos funerarios en la Baja Andalucía, vid. Quesada Sanz 2001; 2008, 155-161; Sierra Montesinos - Pérez Daza 2002; Pérez Daza 2003. Carro de Montemayor: comunicación personal del Equipo del proyecto, a quien se lo agradezco.

139 Caballero Cobos 2008, 299-300.
} 
fue abandonada en el siglo II a.C., aunque en este caso su amortización coincidió claramente con la destrucción y abandono definitivo del poblado. ${ }^{140}$ Otro tanto sucede con el cementerio de Cortijo del Duque, dependiente del Cerro de la Cruz de Puebla de Don Fadrique, destruido seguramente unas décadas después, a finales del siglo II a.C. Es más, en este caso no solo se dejaron de practicar enterramientos en la necrópolis, sino que sobre la misma se instauró un establecimiento rural, en una auténtica demostración de violencia simbólica. ${ }^{141}$

También pueden argüirse, sin embargo, ejemplos de perduración en las prácticas funerarias ibéricas a lo largo del período, circunscritas fundamentalmente a los oppida principales que prosperaron en época iberorromana. Es el caso de la necrópolis de Tutugi, que permaneció en uso hasta el siglo I a.C. ${ }^{142}$ Pero asimismo el de Iliberri, para la que conocemos distintos espacios necropolitanos asociables a los siglos II y I a.C. ${ }^{143} \mathrm{E}$ igualmente es el caso de $A c c i$, donde, pese a que por el momento no se han documentado contextos funerarios de la época, tenemos noticias de hallazgos fortuitos a los pies del cerro datables hacia finales del siglo I a.C., esto es, contemporáneos precisamente con la promoción colonial de la ciudad. ${ }^{144}$

Según la sugerente y creemos que acertada lectura de A. M. Adroher y A. Caballero, ${ }^{145}$ el gran impulso colonizador orquestado desde los grandes oppida nucleares bastetanos desde el siglo IV a.C. llevó a la necesidad de crear nuevos espacios sacros que naturalizaran las nuevas fronteras de unos territorios políticos que ya habían desbordado claramente el entorno inmediato de los poblados. Por consiguiente, las necrópolis, sitas en la periferia de los núcleos urbanos, perdieron esta función fronteriza y paulatinamente dieron paso al surgimiento de los llamados santuarios bastetanos, en un proceso heterogéneo que dependió de las circunstancias de cada poblado y cada territorio. Por supuesto, las elites continuarían enterrándose en las inmediaciones de sus oppida, pero lo harían invirtiendo menos recursos, lo que inevitablemente hubo de reducir la visibilidad de sus sepulturas en el registro arqueológico. Y es que los referentes identitarios, cívicos, de la comunidad se habían desplazado de las necrópolis a los santuarios.

Los llamados santuarios bastetanos fueron unos espacios singulares extraurbanos que no parecen tener parangón fuera de la Bastetania (aunque sí exceden ligeramente la región objeto de este estudio, pues conocemos casos en Almería, Murcia y Jaén ${ }^{146}$ ), que florecieron entre los siglos IV y I a.C. (aunque con un mayor auge en el siglo II a.C.) y que se localizaron dispersos por el territorio político de los oppida, ora en su vecindad inmediata, ora junto a las necrópolis o reaprovechando el solar de cementerios abandonados, ora en sus fronteras periféricas. Se trata de espacios al aire libre de menos de $1000 \mathrm{~m}^{2}$ en los que se detecta una extraordinaria concentración de artefactos singularmente homogéneos: cuencos de borde entrante y platos de borde recto divergente, ambos de pastas claras, y ollas de cocina de pasta grosera y cocción reductora. Significativamente, y a pesar de las cronologías en las que nos estamos

\footnotetext{
140 Quesada Sanz et alii 2014, 236.

141 Adroher Auroux 2008, 237.

142 Rodríguez-Ariza 2014, 153.

143 Sánchez Moreno 2015, 520.

144 Adroher Auroux - López Marcos 2002, 21-23.

145 Adroher Auroux - Caballero Cobos 2012, 241-243.

146 López Mondéjar 2010; Adroher Auroux - Caballero Cobos 2012.
} 
moviendo, las importaciones itálicas no tienen cabida en este tipo de depósitos, ${ }^{147} \mathrm{ni}$ tampoco la imagen figurativa, a diferencia de lo que sucede en los santuarios de las regiones aledañas en estas mismas fechas y pese a que en algunos de ellos se acumuló una facies cerámica parecida. ${ }^{148}$

Este último dato, de hecho, no es precisamente baladí: en la mayoría de los santuarios iberorromanos murcianos, albaceteños, giennenses y cordobeses, la representación figurativa de los devotos que visitaban el lugar devino una constante fundamental; como también lo fue, al menos en determinados casos, la construcción de una cella y la monumentalización de lo que hasta esos momentos habían sido santuarios al aire libre. ${ }^{149}$ Este tipo de santuarios resulta excluyente respecto de los llamados santuarios bastetanos, de tal manera que en los territorios en los que surgen unos, no surgen los otros, y viceversa. Pareciera, pues, como si las elites bastetanas no hubieran experimentado el afán de sus homólogas de invertir grandes cantidades de recursos en singularizar su paso por los santuarios colectivos y en negociar a través de ellos su distinción. En los llamados santuarios bastetanos, a diferencia de los espacios sacros de otras áreas, el ritual no cambió a lo largo de todo el período iberorromano, primando en todo momento unas prácticas homogéneas que parecen ensalzar la idea de la comunitas tradicional por encima de cualquier otra noción jerarquizadora. Aunque tampoco carguemos demasiado los términos. No olvidemos que estos llamados santuarios bastetanos solo se extendieron por la Bastetania nororiental ${ }^{150}$ en tanto que en otras zonas consideradas bastetanas, como la vega granadina, encontramos espacios sacros más parecidos a los del sureste, caso del santuario de Ilurco con sus famosos exvotos de caballos. ${ }^{151}$

Podría argüirse que los relieves de Ilurco constituyen una "intrusión" de iconografía alóctona. Pero no olvidemos que en el corazón mismo de la Bastetania, en la necrópolis de Cerro Largo dependiente del poblado de Basti, apareció, sin contexto arqueológico conocido, un busto de varón de $61 \mathrm{~cm}$ de altura y con restos de policromía que cabría datar en el siglo II a.C. ${ }^{152}$ La pieza, un verdadero "thoracato a la ibérica" en palabras de T. Chapa, representa a un varón que portaba, bajo un grueso manto abrochado sobre el hombro derecho, una túnica de manga larga y cuello en pico y se adornaba con las tiras cruzadas bajo el cuello típicas de los guerreros ibéricos. ${ }^{153}$ La parte trasera del busto estaba horadada, quizás para recibir las cenizas del difunto, como sabemos que sucedió, entre otras esculturas ibéricas de épocas anteriores, con la propia Dama de Baza. El brazo izquierdo del personaje permanece oculto bajo el manto, mientras que el derecho se dobla a la altura del codo, como sosteniendo los pliegues de este. ${ }^{154}$ Nuestra pieza no representa a un togado como los que en el siglo II a.C. comienzan a aparecer en

147 Adroher Auroux - Caballero Cobos 2012.

148 Rodríguez-Ariza et alii 2008. Recuérdese que el llamado "relieve de la Danza Bastetana" apareció en realidad en el santuario de Las Atalayuelas (Fuerte del Rey, Jaén), fuera por tanto de la Bastetania, y que, aunque tradicionalmente se ha relacionado con la noticia de Estrabón acerca de los bailes tradicionales bastetanos (Str. 3.3.7), en realidad posiblemente estuviera representando a una familia de devotos (Prados Torreira 2014, 401403).

149 Tortosa Rocamora - Ramallo Asensio 2017.

150 Adroher Auroux - López Marcos 2002, 23-25 y 32-33.

151 Cuadrado Díaz - Ruano Ruiz 1989.

152 Chapa Brunet - Olmos Romera 1999, 36-37.

153 Chapa Brunet 2008, 38-41.

154 Chapa Brunet - Olmos Romera 1999, 36-37. 
los santuarios ibéricos de las comarcas circundantes a la Bastetania, ${ }^{155}$ sino a un jerarca ibérico que no solo viste a la ibérica, sino que recupera en sus atuendos, e incluso en su mismo modo de enterrarse valiéndose de una estatua-urna, usos y costumbres ancestrales. Un aristócrata ibérico cuyos deudos quizás trataron de subrayar su "iberismo" durante su sepelio, pero que a la altura del siglo II a.C. no pudieron ya sustraerse del todo a las modas ni, por supuesto, a las estructuras ideológicas hegemónicas en el Mediterráneo helenístico.

\section{Conclusiones}

Sin pretender definir las difusas fronteras de la Bastetania, en estas páginas hemos tratado de profundizar en las dinámicas políticas, sociales, económicas y culturales que caracterizaron el devenir de las comunidades locales de la región durante la época posterior a la conquista romana y su problemática relación con el aparato imperial romano, partiendo de la hipótesis de que la realidad histórica hubo de ser demasiado compleja para intentar encuadrarla en la dicotomía resistenciapacificación, manoseada hasta la saciedad por la historiografía tradicional y sus presupuestos colonialistas.

A lo largo de la Segunda Guerra Púnica, la Bastetania constituyó un escenario de retaguardia en el que las comunidades locales se vieron transidas por unas tensiones internas que cartagineses y romanos trataron de explotar. La región, sin embargo, nunca llegó a convertirse en el principal frente de guerra, por lo que al final del conflicto quedó convertida en un enclave apenas afectado por la expansión imperial romana, rodeado por toda una serie de espacios mucho mejor controlados por el aparato provincial. A partir de los años 90 del siglo II a.C., sin embargo, Roma emprendió toda una serie de expediciones militares discontinuas y de alcance limitado que, no sin reveses, fueron integrando el enclave bastetano en las estructuras provinciales hispanas. La destrucción sistemática del complejo aristocrático que un señor de la guerra local utilizaba como centro de poder local en el Cerro de la Merced, en las cercanías de Licabro-Cabra, demuestra, según vimos en su momento, que este paulatino proceso de integración no estuvo exento de tensiones y de episodios violentos. De hecho, esta integración tardó en consolidarse, como parece revelar el hecho de que Viriato extendiera sus campañas hasta la región para intentar soliviantar a las recientemente anexionadas comunidades bastetanas contra el poder romano, cosechando, al parecer, una buena, aunque efímera, acogida, y provocando los correspondientes episodios de represión en cuanto los romanos recuperaron el control de la situación, según señalan las crónicas de la época y sugieren los niveles de destrucción del Cerro de la Cruz de Almedinilla.

Tras el sangriento episodio protagonizado por Viriato, la Bastetania desaparece de nuestras fuentes escritas, lo que no hubo de significar forzosamente su integración definitiva. Así parece demostrarlo la estructura de poblamiento: frente a un continuismo general de las dinámicas regionales activas desde siglos anteriores, apenas salpicado de ciertas destrucciones puntuales coincidentes con la Segunda Guerra Púnica y con las guerras lusitanas, será durante la segunda mitad del siglo

155 García Cardiel 2019. 
II a.C. cuando se produzca el abandono de los poblados y fortalezas secundarias que controlaban las fronteras de los oppida nucleares y sus principales vías de comunicación. El ocultamiento de tesoros a finales del siglo II a.C., no solo en los valles bastetanos, sino en general en toda la Bética, parece hablar de un período de inestabilidad que afectó más a unas comunidades que a otras. Todo apunta a que a lo largo de esta segunda mitad de la centuria el aparato provincial romano se fue fortaleciendo en la zona sin que ello fuera necesariamente en detrimento de la pervivencia e incluso de la prosperidad de los principales núcleos de poder local.

Así parecen demostrarlo igualmente las actividades productivas locales. Las primeras centuriaciones no se producen en la región hasta finales del siglo I a.C., momento hasta el cual las villae tampoco comienzan a desplazar a los pequeños asentamientos rurales ibéricos, salvo en las regiones por las que estos aún no se habían difundido. Aparecen, bien es cierto, referencias a ciertos publicani que participarían del proceso de extracción y transformación minerometalúrgica, pero posiblemente actuaban en colaboración con los poderes locales y adecuándose a los modelos tradicionales de producción. Por su parte, las escasas cecas de la región emiten acuñaciones esporádicas que podrían responder únicamente a necesidades coyunturales. Tan es así que, significativamente, Iliberri acuña sus primeras monedas con leyendas en latín y las siguientes, sumamente espaciadas en el tiempo, con silabario ibérico. El grueso de los intercambios, no obstante, continuaron llevándose a cabo según los usos y costumbres locales, en los que la economía monetaria tardaría en abrirse camino.

Lo mismo puede decirse, en fin, en lo referido al culto y los espacios sagrados. A diferencia de las regiones vecinas, cuyos santuarios se monumentalizaron, adecuando la escenografía del rito, y posiblemente también el rito mismo, a las nuevas sensibilidades mestizas, los llamados santuarios bastetanos continuaron prodigándose hasta el cambio de Era. Tan es así, de hecho, que la cerámica campaniense no parece tener cabida entre los recipientes amortizados. Ello es consecuente con la escasa, pero sumamente significativa, iconografía figurativa documentada en la región: en este sentido, el llamado guerrero de Baza parece una verdadera reivindicación de la identidad ancestral del aristócrata representado, que sin embargo no puede sustraerse, acaso inadvertidamente, a las nuevas modas helenísticas.

El enclave bastetano, en cuanto que enclave, auténtico mundo de frontera a caballo entre las dos provincias hispanas, desaparece a la altura del cambio de Era. Seguramente la reestructuración provincial augustea tuvo mucho que ver en ello: la transformación del poblamiento a resultas de la potenciación de la Vía Augusta, la centuriación de los campos en torno a algunas de las principales ciudades bastetanas, la aparición de las primeras villae y la puesta en explotación de los yacimientos auríferos hablan de profundos cambios sociales, políticos y económicos. También los santuarios bastetanos se dieron por cancelados, por mucho que los oppida nucleares que los impulsaban pervivieran, transformados en colonias y municipios. Las dificultades que los autores altoimperiales se encontraron a la hora de tratar de definir qué fue la Bastetania y cuáles fueron sus límites son significativas de la rápida disolución de esas afinidades culturales hasta entonces imperantes. Y más aún lo es la circunstancia de que, cuando con Augusto se modificaron los límites interprovinciales, la nueva frontera entre provincias se trazó, precisamente, a través de los territorios bastetanos, dejando algunas de sus ciudades en la Bética y otras 
en la Tarraconense. ${ }^{156}$ Ello explicaría la aparición en el siglo I d.C. de una regio Bastetana, verdadero elemento de definición étnica, solo parcialmente coincidente con la "Bastetania histórica" de las centurias anteriores que ha sido el objeto de análisis de las presentes páginas.

\section{Referencias bibliográficas}

Adroher Auroux, A. M. (2008): "La Bastetania arqueológica. Estado de la cuestión", [en] Adroher Auroux - Blánquez Pérez (eds.), 2008, 211-246.

Adroher Auroux, A. M. - Blánquez Pérez, J. J. (eds.), (2008): I Congreso Internacional de Arqueología Ibérica Bastetana (=UAM. Varia 9), Madrid.

Adroher Auroux, A. M. - Brao, F. J. - Bravo, A. D. - Caballero, A. - Godoy, R. - Guerrero, A. - López, A. - López, M. P. - Morales, E. - Salvador, J. A. - Sánchez, F. J. - Sánchez, A. (2004): "La fortificación romana del Cerro del Trigo. Perspectivas arqueográficas", [en] Adroher Auroux - López Marcos (dirs.), 2004, 243-262.

Adroher Auroux, A. M. - Caballero Cobos, A. (2012): "Santuarios y necrópolis fuera de las murallas: el espacio periurbano de los oppida bastetanos", [en] M. C. Belarte - R. Plana Mallart (eds.), El paisatge periurbà a la Mediterrània occidental durant la protohistòria i l'antiguitat (=ICAC. Documenta 26), Tarragona, 231-244.

Adroher Auroux, A. M. - Caballero Cobos, A. - Sánchez Moreno, A. (2005): "El oppidum ibérico de Ilturir-Iliberri”, [en] C. Vílchez Vílchez et alii (coords.), Los vidrios griegos en Granada, Granada, 75-86.

Adroher Auroux, A. M. - López Marcos, A. (2002): "El impacto romano sobre los asentamientos ibéricos en la Alta Andalucía: las Intrabéticas septentrionales", [en] C. González Román - A. R. Padilla Arroba (coords.), Estudios sobre las ciudades de la Bética, Granada, 9-48.

Adroher Auroux, A. M. - López Marcos, A. (dirs.), (2004): El territorio de las altiplanicies granadinas entre la Prehistoria y la Edad Media. Arqueología en Puebla de Don Fadrique (1995-2002), Sevilla.

Adroher Auroux, A. M. - López Marcos, A. - Pachón Romero, J. A. (2002): La cultura ibérica, Granada.

Almagro Gorbea, M. (1982): “Tumbas de cámara y cajas funerarias ibéricas. Su interpretación socio-cultural y la delimitación del área cultural ibérica de los bastetanos", [en] En homenaje a Conchita Fernández Chicarro, Madrid, 249-257.

Bádenas de la Peña, P. - Cabrera Bonet, P. - Moreno Conde, M. - Ruiz Rodríguez, A. Sánchez Fernández, C. - Tortosa Rocamora, T. (eds.), (2014): Homenaje a Ricardo Olmos. Per speculum in aenigmate. Miradas sobre la Antigüedad (=ACHH. Anejos de Erytheia, Estudios y Textos 7), Madrid.

Bellón Ruiz, J. P. - Ruiz Rodríguez, A. - Molinos Molinos, M. - Rueda Galán, C. - Gómez

156 Plin. $H N$ 3.12. Sobre la Bastetania y el traslado de la frontera interprovincial, vid. Casado 2007. El reciente descubrimiento en Mengíbar del llamado Arco de Jano por parte del equipo dirigido por J. P. Bellón Ruiz (https://www.europapress.es/andalucia/noticia-localizado-mengibar-jaen-arco-jano-marca-entrada-beticaromana-20180522181939.html; consultado el 23/10/2019) confirmaría el traslado de la frontera deducido a partir del recuento pliniano. Es en estos momentos cuando algunas de las interpretaciones más recientes sitúan el surgimiento de la regio Bastetania como unidad de recaudación fiscal, independiente en lo territorial y en lo identitario respecto de las realidades poblacionales previas: cf. Salvador Oyonate 2015. 
Cabeza, F. (eds.), (2015): La Segunda Guerra Púnica en la Península Ibérica. Baecula, arqueología de una batalla, Jaén.

Bellón Ruiz, J. P. - Ruiz Rodríguez, A. - Molinos Molinos, M. - Rueda Galán, C. - Gómez Cabeza, F. - Quesada Sanz, F. (2015): “Conclusiones y propuestas sobre el desarrollo de la Batalla de Baecula", [en] Bellón Ruiz et alii (eds.), 2015, 537-599.

Blanco Freijeiro, A. - Lachica, G. (1960): “De situ Iliturgis", Archivo Español de Arqueología 33, 193-196.

Blech, M. (2008): "El urbanismo ibérico en el sur peninsular bajo una perspectiva externa", [en] Adroher Auroux - Blánquez Pérez (eds.), 2008, 93-104.

Bravo Carrasco, A. D. - Sánchez García, F. J. - Adroher Auroux, A. M. - Caballero Cobos, A. (2004): "Conquista romana, rebelión y repercusión en la sociedad ibérica: el Campo de Bugéjar (ss. II-I a.C.)”, [en] Adroher Auroux - López Marcos (dirs.), 2004, 219-242.

Caballero Cobos, A. (2008): “Basti ibérica”, [en] Adroher Auroux - Blánquez Pérez (eds.), 2008, 299-315.

Campos Carrasco, J. M. - Bermejo Meléndez, J. (eds.), (2018): Ciudades Romanas de la Provincia Baetica II. Conventus Hispalensis et Astigitanus, Huelva.

Carrasco Rus, J. - Pachón Romero, J. A. (1998): "Fíbulas de codo tipo Huelva de Montejícar, Granada", Florentia Iliberritana 9, 423-443.

Casado Baena, M. (2007): "Localización de la antigua ciudad de Urci y delimitación de la frontera interprovincial entre las provincias Bética y Tarraconense en tiempos de Tolomeo", Gerión 25/1, 391-400.

Chapa Brunet, T. (2008): "Escultura y definición de áreas culturales: el caso de la Bastetania", [en] Adroher Auroux - Blánquez Pérez (eds.), 2008, 29-50.

Chapa Brunet, T. - Olmos Romera, R. (1999): "El busto de varón de Baza (Granada). Una propuesta de lectura", [en] C. San Martín Montilla - M. Ramos Lizana (eds.), El guerrero de Baza, Sevilla, 33-40.

Chapa Brunet, T. - Pereira Sieso, J. (1994): "Las etnias prerromanas del sureste: problemas de su comprobación arqueológica”, [en] II Congreso de Historia de Andalucía, Córdoba, vol. 3, 89-105.

Chapa Brunet, T. - Pereira Sieso, J. - Madrigal Belinchón, A. (1999): “El poblamiento de época ibérica en el área del Guadiana Menor: el caso de los Castellones de Ceal (Hinojares, Jaén)", [en] V. Salvatierra Cuenca - C. Rísquez Cuenca (eds.), De las sociedades agrícolas a la Hispania romana (=Colección Martínez de Mazas, Serie Estudios 20), Jaén, 81-93.

Chaves Tristán, F. (1996): Los tesoros en el sur de Hispania. Conjuntos de denarios y objetos de plata durante los siglos II y I a.C., Sevilla.

Chic García, G. (1980): “Consideraciones sobre las incursiones lusitanas en Andalucía”, Gades 5, 15-25.

Corzo Sánchez, R. (1975): “La Segunda Guerra Púnica en la Bética”, Habis 6, 213-240.

Cuadrado Díaz, E. - Ruano Ruiz, E. (1989): "Esculturas de équidos procedentes de la colección de Alhonoz (Puente Genil, Córdoba)", Trabajos de Prehistoria 46, 203-228.

Díaz Ariño, B. (2009): "La Hispania Citerior, desarrollo económico e integración en época republicana: una aproximación epigráfica", Dialogues d'histoire Ancienne 35/1, 115-152 (https://doi.org/10.3406/dha.2009.3096).

Domergue, C. (1990): Les mines de la Péninsule Ibérique dans l'Antiquité romaine (=Collection de l'École française de Rome 127), Paris.

Domínguez Monedero, A. J. (2015): "Los autores antiguos y la Segunda Guerra Púnica. Una visión sesgada", [en] Bellón Ruiz et alii (eds.), 2015, 29-48. 
Fernández-Götz, M. A. (2009): “La etnicidad desde una perspectiva arqueológica: propuestas teórico-metodológicas”, ETF, Serie II. H ${ }^{a}$ Antigua 22, 187-199 (http://dx.doi.org/10.5944/ etfii.22.2009.1743).

Ferrer Albelda, E. - Prados Pérez, E. (2001-2002): "Bastetanos y bástulo-púnicos. Sobre la complejidad étnica del Sureste de Iberia", Anales de Prehistoria y Arqueología 17-18, 273-282.

Garcés Estallo, I. (2008): "Bastetania, ¿enemiga o aliada de Roma? Análisis de dos interpretaciones históricas”, [en] Adroher Auroux - Blánquez Pérez (eds.), 2008, 105124.

García-Bellido, Ma P. - Blázquez Cerrato, C. (2001): Diccionario de cecas y pueblos hispánicos, Madrid.

García Cano, J. M. (2008): "Los bastetanos más orientales del mar al interior. Las tribus ibéricas en la región de Murcia", [en] Adroher Auroux - Blánquez Pérez (eds.), 2008, 105-124.

García Cardiel, J.

(2016): Los discursos del poder en el mundo ibérico del Sureste (siglos VII-I a.C.), (=CSIC. Bibliotheca Praehistorica Hispana 32), Madrid.

(2019): "Revestir el poder en tiempos de cambio: el uso de la toga entre las elites ibéricas (ss. II-I a.C.)", Archivo Español de Arqueología 92, 155-171 (http://dx.doi.org/10.3989/ aespa.092.019.008).

García Moreno, L. (1990): "Mastienos y bastetanos. Un problema de la etnología hispana prerromana", Polis 2, 53-85.

García Pulido, J. L. (2014): El oro aluvial de la provincia de Granada, Granada.

González Román, C. (1992): "La Colonia Iulia Gemella Acci y la evolución de la Bastetania", Dialoghi di Archeologia 10/1-2, 155-164.

González Román, C. - Adroher Auroux, A. M. (1999): "El poblamiento ibero-bastetano: consideraciones sobre su morfología y evolución”, [en] F. Villar Liébana - F. Beltrán Lloris (eds.), Pueblos, lenguas y escrituras en la Hispania prerromana (=Ediciones Universidad de Salamanca. Estudios Filológicos 273), Salamanca, 243-255.

González Román, C. - Adroher Auroux, A. M. - López Marcos, A.

(1997): "El Peñón de Arruta (Jerez del Marquesado, Granada): una explotación minera romana", Florentia Iliberritana 8, 183-213.

(2001): "El Cardal (Ferreira), una explotación minera de los siglos III y II a.C. en las laderas septentrionales de Sierra Nevada (Granada)", Florentia Iliberritana 12, 199220.

Gozalbes Cravioto, E.

(2000): "Sobre la ubicación de ciudades romanas en la Bética Oriental. Algunos problemas de las fuentes literarias", Antiquitas 11, 41-46.

(2008): "Ubi sunt Bastetani? (De Ávila a Extremadura pasando por Baza)", [en] Adroher Auroux - Blánquez Pérez (eds.), 2008, 271-281.

López Castro, J. L - Adroher Auroux, A. M. (2008): “Andalucía oriental durante el I milenio a.C.: la costa fenicia y la bastetania ibera", Mainake 30, 145-156.

López Castro, J. L. - Martínez Hahnmüller, V. (2012): “'Baria’ en la Segunda Guerra RomanoCartaginesa: su papel histórico a través de la documentación literaria y arqueológica”, [en] S. Remedios Sánchez - F. Prados Martínez - J. Bermejo Tirado (eds.), Aníbal de Cartago. Historia y mito, Madrid, 329-344.

López Marcos, A. (2008): "El oppidum ibérico de Acci (Guadix)", [en] Adroher Auroux Blánquez Pérez (eds.), 2008, 287-298. 
López Mondéjar, L.

(2008): "La definición de los bastetanos en la historiografía. Enfoques para un estudio del mundo ibérico murciano", [en] Adroher Auroux - Blánquez Pérez (eds.), 2008, 11-22. (2010): "Los santuarios ibéricos del valle del Quípar (Murcia): carácter, localización y paralelos en el marco del sureste peninsular", Quaderns de prehistòria i arqueología de Castelló 28, 174-189.

(2018): El mundo ibérico en el sureste peninsular. Los territorios meridionales murcianos, Madrid.

Lorrio Alvarado, J. (2007): “Celtíberos y bastetanos en el oriente de la Meseta Sur: problemas de delimitación territorial", [en] G. Carrasco (coord.), Los pueblos prerromanos en Castilla-La Mancha (=Ediciones de la Universidad de Castilla-La Mancha. Colección Humanidades 92), Cuenca, 227-270.

Lozano Rodríguez, J. A. - Gámez-Layva Hernández, M. L. - Ruiz Puertas, G. - Hódar Correa, M. (2008): "Denominación, edad y funcionalidad del depósito de agua hallado entre las calles Álamo del Marqués y San José (Albaicín, Granada)", [en] Adroher Auroux - Blánquez Pérez (eds.), 2008, 117-130.

Marín Díaz, N. - Pérez Cruz, M.A. (1996): “La regio Bastitania et le debut de sa romanisation”, Dialogues d'Histoire Ancienne 22/2, 251-256 (https://doi.org/10.3406/dha.1996.2721).

Marín Díaz, N. - Puentedura Béjar, M. (1994): "Elementos fósiles para la interpretación del parcelario en época romana. Un caso: Colonia Iulia Gemella Acci”, [en] S. M. Ordóñez Águila - P. Sáez Fernández (coords.), Homenaje al profesor Presedo, Sevilla, 547-554.

Martínez López, C. - Muñoz Muñoz, F. A. (1999): Poblamiento ibérico y romano en el sureste peninsular: la Comarca de los Vélez (Almería), Granada.

Mayoral Herrera, V. (2004): Paisajes agrarios y cambio social en Andalucía oriental entre los periodos ibérico y romano (=Anejos de AEspA 31), Mérida.

Morales Rodríguez, E. V. - Castillo Rueda, M. A. (2009): "El ager ilurconensis", Florentia Iliberritana 20, 269-308.

Morena López, J. A. (2017): Arquitectura, iconografía y culto en el santuario iberorromano de Torreparedones (Baena, Córdoba), Córdoba.

Muñiz Jaén, I. - Quesada Sanz, F. (eds.), (2010): Un drama en tres actos. Dos milenios de ocupación humana en el Cerro de la Cruz (Almedinilla, Córdoba), (=Oikos 2), Almedinilla.

Ñaco del Hoyo, T. (2017): “Conectividad, integración militar y estrés bélico en el N.E. de Hispania Citerior (c. 125-100 a.C.)", [en] J. Principal i Ponce - T. Ñaco del Hoyo - M. Durán i Caixal - I. Mestres Santacreu (eds.), Roma en la Península Ibérica presertoriana. Escenarios de implantación militar provincial (=Universitat de Barcelona. Col·lecció Instrumenta 56), Barcelona, 17-38.

Ñaco del Hoyo, T. - López Sánchez, F. (eds.), (2017): War, Warlords and Interstate Relations in the Ancient Mediterranean (=Impact of Empire 28), Leiden (https://doi. org/10.1163/9789004354050).

Pachón Romero, J. A. (2008): "Más allá de Iliberri. Ibéricos en las depresiones orientales granadinas", [en] Adroher Auroux - Blánquez Pérez (eds.), 2008, 247-265.

Pachón Romero, J. A. - Fuentes Vázquez, T. - Hinojosa Pareja, A. R. (2004): "Plomo con leyenda ibérica de Los Allozos, Montejícar (Granada)", Habis 35, 151-177.

Padilla Arroba, Á. (2016): "Un tesorillo romano republicano del siglo II a.C. procedente del territorio accitano (Guadix, Granada)", Revista del CEHGR 28, 105-128.

Pastor Muñoz, M. (1993): "Los bastetanos en las fuentes clásicas", [en] I Coloquio de Historia Antigua de Andalucía, Córdoba, vol. 1, 213-233. 
Pérez Cruz, M. Á. (1997): "La comunidad bastetana en la Antigüedad", Florentia Iliberritana 8, 383-400.

Pérez Daza, F. (2003): "Nueva aportación al estudio del armamento ibérico en la línea Almedinilla-Porcuna-Andújar", Antiquitas 15, 59-64.

Pérez Vilatela, L. (1989): "Procedencia geográfica de los lusitanos de las guerras del siglo II a. de C. en los autores clásicos (154-139)", [en] VII Congreso Español de Estudios Clásicos, Madrid, vol. 3, 257-262.

Prados Torreira, L. (2014): "Las representaciones de grupos familiares en los santuarios de la cultura ibérica”, [en] Bádenas de la Peña et alii (eds.), 2014, 400-405.

Quesada Sanz, F.

(1992): "Notas sobre el armamento ibérico de Almedinilla", Anales de Arqueología Cordobesa 3, 113-135.

(2001): "Rellenando los mapas: nuevos conjuntos funerarios ibéricos con armas en la provincia de Córdoba", Antiquitas 13, 71-101.

(2008): "Entre bastetanos y turdetanos: arqueología ibérica en una zona de fronteras", [en] Adroher Auroux - Blánquez Pérez (eds), 2008, 147-177.

(2015): "La batalla de Baecula en el contexto de los ejércitos, la táctica y la estrategia de mediados de la Segunda Guerra Púnica: una acción de retaguardia reñida", [en] Bellón Ruiz et alii (eds.), 2015, 601-620.

Quesada Sanz, F. - Camacho Calderón, M. (2014): "El recinto fortificado ibérico tardío del Cerro de la Merced (Cabra) y un posible monumento ibérico previo. Un problema de puntos de vista", [en] Bádenas de la Peña et alii (eds.), 2014, 406-415.

Quesada Sanz, F. - Kavanagh de Prado, E. - Lanz Domínguez, M. (2014): "Los molinos del yacimiento del Cerro de la Cruz (Almedinilla, Córdoba): clasificación y análisis de los ejemplares de época ibérica y emiral", Spal 23, 83-118 (https://doi.org/10.12795/ spal.2014.i23.05).

Quesada Sanz, F. - Kavanagh de Prado, E. - Moralejo Ordax, J. (2010): “El asentamiento de época ibérica en el Cerro de la Cruz”, [en] Muñiz Jaén - Quesada Sanz (eds.), 2010, 75-95.

Quesada Sanz, F. - Lanz Domínguez, M. - Moreno Rosa, A. - Kavanagh de Prado, E. Gaspar Guardado, D. - Camacho Calderón, M. - Saldaña Puentes, R. M. - Carvajal Rada, T. (2015): "Excavaciones en el recinto fortificado ibérico del Cerro de la Merced (Cabra, Córdoba). Resultados preliminares", [en] Ó. Rodríguez Monterrubio - R. Portilla Casado - J. C. Sastre Blanco - P. Fuentes Melgar (eds.), Fortificaciones en la Edad del Hierro: control de los recursos y el territorio, Valladolid, 441-448.

Quesada Sanz, F. - Muñiz Jaén, I. - López Flores, I. (2014): “La guerre et ses traces: destruction et massacre dans le village ibérique du Cerro de la Cruz (Cordoue) et leur contexte historique au IIe s. a.C.", [en] F. Cadiou - M. Navarro Caballero (eds.), La guerre et ses traces. Conflits et sociétés en Hispanie à l'époque de la conquête romaine (IIIe-Ier s. a.C.), (=Ausonius Éditions. Mémoires 37), Bordeaux, 231-271.

Rodríguez-Ariza, M. O. (2014): La necrópolis ibérica de Tútugi (2000-2012), Jaén.

Rodríguez-Ariza, M. O. - Rueda Galán, C. - Gómez Cabeza, F. (2008): “El posible santuario periurbano de Tutugi: el Cerro del Castillo (Galera, Granada)", [en] Adroher Auroux Blánquez Pérez (eds.), 2008, 187-203.

Roldán Hervás, J. M. - Wulff Alonso, F. (2001): Citerior y Ulterior. Las provincias romanas de Hispania en la era republicana, Madrid.

Román Punzón, J. M. (2009): "Un asentamiento rural de época romana en la vega de Granada: el Cerro de la Mora (Moraleda de Zafayona, Granada)", Anales de Arqueología Cordobesa 20, 231-256 (https://doi.org/10.21071/aac.v20i.6954). 
Roselaar, S. T. (2012): "Mediterranean trade as a mechanism of integration between Romans and Italians", [en] S. T. Roselaar (ed.), Processes of integration and identity formation in the Roman Republic (=Mnemosyne Suppl. 342), Leiden, 141-158 (https://doi. org/10.1163/9789004229600_010).

Ruiz López, I. D. (2011): “Circulación monetaria de las cecas localizadas en la provincia de Granada durante el período romano-republicano", Florentia Iliberritana 22, 297-323.

Ruiz Rodríguez, A. - Hornos Mata, F. - Rísquez Cuenca, C. (1992a): “Las necrópolis ibéricas en la Alta Andalucía", [en] J. J. Blánquez Pérez - V. Antona del Val (eds.), Congreso de Arqueología Ibérica: las necrópolis, Madrid, 397-430.

Ruiz Rodríguez, A. - Castro López, M. - Choclán Sabina, C. (1992b): “Aurgi-Tucci: la formación de la ciudad romana en la Campiña Alta de Jaén", Dialoghi di Archeologia $1-2,211-229$.

Salvador Oyonate, J. A.

(2011): La Bastitania romana y visigoda: arqueología e historia de un territorio, Tesis doctoral, Universidad de Granada.

(2015): "La Regio Bastitana como problema histórico", Florentia Iliberritana 26, 149179.

Sánchez Moreno, A. (2015): La formación del oppidum de Iliberri y la formación diacrónica de su territorio, Granada.

Schulten, A. (1933): Las guerras de 237-154 a. de J.C. (=FHA 3), Barcelona.

Segura Arista, L. (1988): La ciudad ibero-romana de Igabrum (Cabra, Córdoba), Córdoba.

Segura Ramos, B. (2003): "Munda", Faventia 25/1, 179-183.

Sierra Montesinos, M. - Pérez Daza, F. (2002): "Nuevas aportaciones al estudio del armamento ibérico en la provincia de Córdoba", Antiquitas 14, 21-33.

Sillières, P. (1990): Les voies de communication de l'Hispanie méridionale (=Publications du Centre Pierre Paris 20), Paris.

Thouvenot, R. (1973): Essai sur la province romaine de la Bétique, Paris.

Tortosa Rocamora, T. - Ramallo Asensio, S. F. (eds.), (2017): El tiempo final de los santuarios ibéricos en los procesos de impacto y consolidación del mundo romano (=Anejos de AEspA 79), Madrid.

Vaquerizo Gil, D. - Quesada Sanz, F. - Murillo Redondo, J. F. (2001): Protohistoria y romanización en la Subbética cordobesa. Una aproximación al desarrollo de la cultura ibérica en el sur de la actual provincia de Córdoba, Sevilla.

Vaquerizo Gil, D. - Quesada Sanz, F. - Murillo Redondo, J. F. - Carrillo Díaz-Pines, J. R. Carmona Berenguer, S. (1994): Arqueología cordobesa. Almedinilla, Almedinilla.

Zamora Merchán, M. (2010): "El territorio y el poblado del Cerro de la Cruz", [en] Muñiz Jaén - Quesada Sanz (eds.), 2010, 49-65. 